\title{
Article \\ Effects of Various Precipitants on Iron Removal from a Zinc Concentrate Pressure Leaching Solution
}

\author{
Claudio A. Leiva ${ }^{1, *(D)}$, María E. Gálvez ${ }^{1}$, Gerardo E. Fuentes ${ }^{2}$, Claudio A. Acuña ${ }^{3}$ and Jannan A. Alcota ${ }^{1}$ \\ 1 Department of Chemical Engineering, Universidad Católica del Norte, Antofagasta 1270709, Chile; \\ mgalvez@ucn.cl (M.E.G.); direccionmia@heuma.cl (J.A.A.) \\ 2 International Consultant, Santiago 7850000, Chile; gerardoerasmofuentes@gmail.com \\ 3 Department of Chemical and Environmental Engineering, Universidad Técnica Federico Santa María, \\ Valparaíso 2390123, Chile; claudio.acunap@usm.cl \\ * Correspondence: cleiva01@ucn.cl; Tel.: +56-552-655-903
}

Citation: Leiva, C.A.; Gálvez, M.E.; Fuentes, G.E.; Acuña, C.A.; Alcota, J.A. Effects of Various Precipitants on Iron Removal from a Zinc

Concentrate Pressure Leaching

Solution. Minerals 2022, 12, 84 .

https://doi.org/10.3390/

$\min 12010084$

Academic Editor: Kenneth N. Han

Received: 6 November 2021

Accepted: 7 January 2022

Published: 12 January 2022

Publisher's Note: MDPI stays neutral with regard to jurisdictional claims in published maps and institutional affiliations.

Copyright: (c) 2022 by the authors. Licensee MDPI, Basel, Switzerland. This article is an open access article distributed under the terms and conditions of the Creative Commons Attribution (CC BY) license (https:/ / creativecommons.org/licenses/by/ $4.0 /)$.

\begin{abstract}
Autoclave leaching of zinc concentrate (Sphalerite) is an environmentally friendly process compared to roasting, which discharges pollutants into the atmosphere. Due to the amount of iron in the final product, a study is proposed to evaluate different reagents for eliminating iron from the autoclave outcome, minimizing $\mathrm{Zn}$ losses. The colloid formation, zinc losses, iron removal, phase separation stage characteristics (sedimentation and filtering), and reagent costs were used to evaluate six-iron precipitating reagents: $\mathrm{CaO}, \mathrm{Na}_{2} \mathrm{CO}_{3}, \mathrm{CaCO}_{3}, \mathrm{NaOH}, \mathrm{MgO}$, and $\mathrm{Ca}(\mathrm{OH})_{2}$. CaO shows $99.5 \%$ iron removal and $87 \%$ zinc recovery. Although $\mathrm{CaO}$ was one of the reagents with significant zinc recovery, it presented operational difficulties in the filtration stage due to the high viscosity of the mixtures. Finally, $\mathrm{Ca}(\mathrm{OH})_{2}$ is the reagent recommended due to its ease of use, zinc yield recovery, electrowinning efficiency, and iron precipitate filtration rate. Zinc recovery was above $80 \%$, while the iron concentration in the solution was below $50 \mathrm{ppm}$.
\end{abstract}

Keywords: precipitants; iron precipitation; zinc concentrate; oxidation

\section{Introduction}

It is well known that national and transnational mining companies, when commercializing their concentrates, lose the opportunity to recover elements of economic interest that are part of copper concentrates [1]. This situation also occurs in the case of other polymetallic concentrates, such as zinc concentrates, whose elements of interest are not necessarily paid to the producer. Many zinc concentrates produced in Bolivia and shipped through Antofagasta and Mejillones (Chile) are sold as concentrates, with zinc grades between $46 \%$ to $50 \%$ [2] and variable contents of silver, indium and germanium, with low gold grades. A typical zinc concentrate contains $50-62 \% \mathrm{Zn}, 0.3-2.5 \% \mathrm{~Pb}$, variable contents of silver, indium, and germanium, with low concentrations of gold and other elements such as $\mathrm{S}, \mathrm{Fe}$ and $\mathrm{SiO}_{2}[1]$.

Obtaining zinc from concentrates is carried out mainly from the roasting process [3-5], to then go through the processes of leaching, purification of the solution and, finally, electrolytic refinery. The roasting stage generates the discharge of pollutants into the atmosphere, which is not sustainable considering the environmental regulations at the national and international levels. To replace the roasting stage, a process is investigated to obtain zinc cathodes from concentrates, using the technology of autoclave leaching under pressure and temperature conditions [2].

A problem with this processing route is the formation of iron sulfate in the concentrate leaching stage. Together with other impurities, this compound generates problems already studied in the subsequent electrowinning process [6-9]. Even low levels of contaminants influence the sputtering of zinc, which leads to a decrease in current efficiency and changes in the morphology of the deposit. 
Saba and Elsherief [10] report the result of a study in which the effect of iron in the zinc electrodeposition process is analyzed; in a concentration range of 50 to $150 \mathrm{mg} / \mathrm{L}$. The presence of iron in the solutions affects the efficiency of the current, which decreases when the concentration of Fe in the electrolyte increases from $82 \%$ with $50 \mathrm{mg} / \mathrm{L}$ of Fe in solution to $53 \%$ with $150 \mathrm{mg} / \mathrm{L}$ of $\mathrm{Fe}$. It is thus required to design a process to efficiently precipitate the iron contained in the leaching solutions of zinc concentrates. These concentrates constitute a complex polymetallic matrix that, to scale the technology, implies the need to optimize iron removal, considering the influencing factors in an industrial process. The zinc concentrate presents variable mineralogy and generates leaching solutions with an iron content that can reach $23 \mathrm{~g} / \mathrm{L}$, with a Fe/Zn mass ratio that varies between 0.1 and 0.5 .

The jarosite, goethite and hematite processes stand out [11-13]. These processes are named after the main precipitated iron compound and have been used for many years in the zinc industry to purify and remove iron [7].

Only the jarosite process is widely used in the Zn industry [14]; however, it tends to produce a large amount of material, but only $28 \%$ of this is iron, characterized by being a toxic residue with the presence of heavy metals, such as $\mathrm{Cd}$, As, and $\mathrm{Zn}$, which represents a disadvantage from the environmental point of view and the operational costs for the control in confined warehouses [15].

Another option is the goethite process $(\alpha-\mathrm{FeOOH})$, which is suitable for treating low iron concentrate [14], due to its precipitation $\mathrm{pH}$ of 3 , higher than the Jarosite process $(1.2<\mathrm{pH}<1.5)$, there are significant losses of zinc (zinc ferrites), as well as a large amount of calcining not completely dissolved. Goethite is characterized by additional treatment alternatives, such as inerting and solidification to obtain a material used in the construction industry. [15].

The third option is the process of hematite $\left(\alpha-\mathrm{Fe}_{2} \mathrm{O}_{3}\right)$, which is assimilated to that of goethite concerning the precipitation of iron that is carried out through the simultaneous oxidation of Fe (II) and the hydrolysis of Fe (III). The reaction occurs in an oxidizing environment and at high temperatures $\left(>185^{\circ} \mathrm{C}\right)$, implying high capital and operating costs. However, hematite has the highest Fe content among the various iron residues. Therefore, it is characterized by a minimal volume of waste generated and presents a high potential for commercialization by-products [16,17].

Considering the need to scale the process at an industrial level and the characteristics of the leaching solutions that were used in this study (high concentrations of Iron); a good option is to use a reagent that regulates the $\mathrm{pH}$ of the solution to favor the hydrolysis and precipitation of the iron. However, it is necessary to consider and analyze aspects of the precipitation process related to fundamental challenges, such as achieving a phase separation that minimizes the loss of the solution containing the value species.

Precipitation is reactive crystallization, which requires the stages of nucleation, growth and aggregation of particles generated from the supersaturation of a solution. Nucleation can be homogeneous or heterogeneous [18]. Homogeneous nucleation spreads rapidly, and an ultra-fine colloidal precipitate is formed within a short time. The crystal growth can develop by transporting the solute to the interface, surface adsorption, surface reaction, desolvation, and release of the heat of crystallization [19].

Supersaturation is the driving force behind crystallization and is generally dependent on the composition of the solution, $\mathrm{pH}$, and temperature. At low supersaturation, nucleation is homogeneous, and the formation of amorphous crystals is avoided. At a higher level of supersaturation, crystal growth is so rapid that the heat of crystallization to the solution becomes difficult; this causes extensions on the crystal surface (amorphous crystals) and affects the phase separation stage $[19,20]$.

Hydrolytic precipitation is one of the essential types of precipitation reactions and it has been established that there is a relationship between hydrolysis and the level of supersaturation [21]. Before forming the hydroxide, the metal ions undergo partial hydrolysis and include soluble hydrolyzed species. Under high supersaturation, these hydrolyzed species polymerize and eventually crystallize due to the loss of solvation water. Due to 
the ease with which high valence cations hydrolyze and polymerize, the products of their hydrolytic precipitation reactions are characterized by being amorphous [22].

An important aspect to consider in the design of precipitation processes is the equilibrium phase. Those conditions indicate the formation of one or another step from a thermodynamic point of view. The analysis of a solubility diagram contributes to evaluating the feasibility of specific stage production. However, depending on the ion interactions, reactions can occur that simultaneously lead to the production of multiple phases, depending on the hydrothermal synthesis circumstances $(\mathrm{pH}$, temperature, time, nature, and dosage of additives). Masindi et al. (2018) evaluated the fractional recovery process of metals from the acid drainage of a coal mine [23] using calcined cryptocrystalline magnesite. They used a semi-pilot reactor and chemical species such as $\mathrm{Fe}, \mathrm{CaSO}_{4} \cdot \mathrm{b} 2 \mathrm{H}_{2} \mathrm{O}, \mathrm{Al}$, $\mathrm{Mn}, \mathrm{Cu}, \mathrm{Zn}, \mathrm{Pb}$, and $\mathrm{Ni}$ recovered through sequential precipitation at different $\mathrm{pH}$ gradients. Geochemical modeling with PHREEQC was used to validate the experimental data. PHREEQC is a computer system that uses numerical approximation methods to relate a set of thermodynamic and physicochemical principles to experimental data using values from databases [24]. PHREEQC calculates the chemical speciation of metals in solution and the saturation indices of mineral phases based on the measured physicochemical parameters of the solution $(\mathrm{pH}, \mathrm{T}$, redox potential, density, concentrations of primary elements, and traces). The saturation indices indicate whether the distinct mineral phases in the solution are supersaturated, in equilibrium, or undersaturated.

On the other hand, co-precipitation is a factor that needs to be considered and impacts the purification of industrial solutions. Co-precipitation can occur by inclusion, occlusion, and surface adsorption [25]. Inclusion is a co-precipitation mechanism that results from homogeneous nucleation; Occlusion occurs by mechanical entrapment of ions in the layers of the crystal, either as solids or liquids. Adsorption is predominant when larger crystals precipitate and long contact times between the phases [22,26]. Ferrihydrite tends to precipitate first due to its low solubility [27], becoming a suitable substrate to adsorb soluble compounds such as phosphates, arsenate, silicates, organics, and heavy metals. Ferrihydrite is presented as interstitial cement with poorly developed crystallinity, in the form of spherical particles with diameters of 2 to $6 \mathrm{~nm}$ [28] and with a high surface area (200-500 $\mathrm{m}^{2} / \mathrm{g}$ ) that is highly reactive [29]. In this sense, $\mathrm{pH}$ control is significant. At higher $\mathrm{pH}$ values, conditions are favored of metastable species such as Ferrihydrite nucleation. As for temperature, it does not have a substantial effect on Fe removal; Nevertheless, Zn losses increase with rising temperature, and this behavior can be attributed to increased $\mathrm{Zn}^{2+}$ adsorption on ferric hydroxides [30].

According to the updated guidelines, the iron precipitation process must be designed with operational parameters on zinc losses in mind. Ferric iron forms complexes with anions such as chloride, fluoride, or sulfate that affect the composition of the $\mathrm{Fe}^{3+}$ hydrolysis product. Factors such as kinetics, temperature, rate of $\mathrm{pH}$ change, and type of neutralizer used affect process performance. The rapid hydrolysis at room temperature is the formation of a low-density ferric hydroxide gel with a large internal surface that favors the adsorption of metal ions and occludes a large amount of mother liquor, making it challenging to filter wash the gel [31].

In addition, a range of waste recovery activities that address iron precipitation in the solution purification stage [30,32-37] stands out in the line of environmental solutions for mining. Separating components from complicated mixtures provides significant technological hurdles in waste treatment. Additionally, in the specific case of the purification of $\mathrm{Zn}$ solutions with high Fe content; the use of ammonium peroxodisulfate as an oxidizing reagent has been evaluated. Process parameters such as $\mathrm{pH}$, temperature, and oxidant concentration were investigated in the precipitation of impurities and zinc losses. Initially, a leaching solution containing $61.64 \mathrm{~g} / \mathrm{L}$ of $\mathrm{Zn}$ and $10.71 \mathrm{~g} / \mathrm{L}$ of Fe; a final solution is achieved with $59.8 \mathrm{~g} / \mathrm{L}$ of $\mathrm{Zn}$ and $5.59 \mathrm{mg} / \mathrm{L}$ of Fe. This represents the removal of $99.4 \% \mathrm{Fe}$ and a $3 \%$ loss of $\mathrm{Zn}$; at a temperature of $90^{\circ} \mathrm{C}, \mathrm{pH} 2.5$, and ammonium peroxodisulfate concentration of $30 \%$ by volume [7]. 
On the other hand, an essential aspect of industrial applications is phase separation. In this context, Tawanda et al. [32] have investigated the behavior of iron-laden wastewater from acid mine drainage. This work explores the effect of the $\mathrm{OH} / \mathrm{Fe}$ molar ratio on the sedimentation and filtration capacity of a precipitated suspension. A stoichiometric and substoichiometric $\mathrm{OH} / \mathrm{Fe}$ ratio of 3 and 2.5 were used. The results showed that the dehydration characteristics of the product depend on the relationship among supersaturation, $\mathrm{pH}$ and ionic strength. The results suggest that treatment plants employing lime neutralization should operate at lower $\mathrm{OH}$ concentrations than current practice to improve the sedimentation and filtration properties of the sludge.

In this study, a universe of six iron precipitating reagents was used: quicklime $(\mathrm{CaO})$, sodium carbonate $\left(\mathrm{Na}_{2} \mathrm{CO}_{3}\right)$, limestone $\left(\mathrm{CaCO}_{3}\right)$, sodium hydroxide $(\mathrm{NaOH})$, magnesium oxide $(\mathrm{MgO})$ and slaked lime $\left(\mathrm{Ca}(\mathrm{OH})_{2}\right)$; which were evaluated at a laboratory scale defining as performance index the \% of removal of $\mathrm{Fe}$, the $\%$ of losses of $\mathrm{Zn}$, the cost of the reagents and their filterability characteristics. The information generated contributes to establishing some control mechanisms for the supersaturation of solutions, aiming to increase iron removal, minimize zinc losses, and ensure adequate phase separation. The work's primary goal presented here is to identify a suitable reagent for industrial usage based on the features of the leaching solutions through laboratory-scale tests. Pilot-scale studies will be carried out in the second stage to purify solutions using the chosen reagent. The practical testing will supplement the geochemical modeling of the system under investigation.

\section{Materials and Methodology}

\subsection{Materials}

The experiments were carried out in the Metallurgical and Mining Engineering Department of the Universidad Católica del Norte. The iron removal process was developed with solutions obtained from the leaching of zinc concentrates in an autoclave reactor. In this, the sulfuric acid solution $\left(\mathrm{H}_{2} \mathrm{SO}_{4}\right)$ at $20 \% w / w$ is mixed with the zinc concentrate $(\mathrm{ZnS})$ in a ratio of mineral mass $(\mathrm{g})$ and volume of leaching solution $(\mathrm{mL})$ of 0.1 . The reactor has a capacity of $1 \mathrm{~L}$ and operates at 40 bar oxygen pressure and a temperature between $200{ }^{\circ} \mathrm{C}$ and $250{ }^{\circ} \mathrm{C}$.

For the solution purification stage, the experimental unit included: a $500 \mathrm{~mL}$ glass reactor, magnetic stirrers, $\mathrm{pH}$ measuring equipment, ORP (oxidation-reduction potential), temperature sensors and vacuum phase separation equipment. The reagents used for iron removal were: $\mathrm{CaO}(\mathrm{s})$ at $99 \%, \mathrm{MgO}(\mathrm{s})$ at $99 \%, \mathrm{Na}_{2} \mathrm{CO}_{3}(\mathrm{~s})$ at $98 \%, \mathrm{CaCO}_{3}$ (s) at $98 \%$, and $\mathrm{NaOH}$ solution with a concentration of $10 \mathrm{M}$ and slaked lime $\left(\mathrm{Ca}(\mathrm{OH})_{2}\right)$, prepared from $\mathrm{CaO}$ with a variable proportion of water and lime.

\subsection{Characterization}

The solids were characterized using Qemscan (Quantitative Evaluation of Minerals by Scanning Electron Microscopy) and the X-ray diffraction method (XRD). The Qemscan (Scientific Equipment Unit, Universidad Católica del Norte, Antofagasta, Chile) is a scanning electron microscope that has been modified both in hardware and software to perform automated identification and quantification of a range of basic definitions that can be associated with solid inorganic phases such as minerals, alloys, and slags, among others. The XRD was performed using a Bruker ${ }^{\circledR}$ Advanced 8 X-ray diffractometer (Scientific Equipment Unit, Universidad Católica del Norte, Antofagasta, Chile), which enables material characterization by detecting the crystalline structure. A diffractogram is produced, which is compared to the database the DIFFRAC.EVA V6 program is used to identify the crystalline phases and enables qualitative evaluation. The Rietveld refinement is used in the DIFFRAC.TOPAS software (Scientific Equipment Unit, Universidad Católica del Norte) to perform the quantification. HORIBA's Digital pH-Meter, Model LAQUA-PH1100, LAQUA, Kyoto, Japan, was used to take the $\mathrm{pH}$ readings. $\mathrm{pH} 4.0$ and $\mathrm{pH} 7.0$ buffer solutions were used to calibrate the device. Potential measurements are a quick and accurate 
way to estimate the oxidizing or reducing capacity of the medium in which the reaction occurs. The redox potential was determined using the same $\mathrm{pH}$ measuring apparatus but with an $\mathrm{Ag} / \mathrm{AgCl}$ electrode and 430-470 [mV] redox solutions instead of the $\mathrm{pH}$ electrode (Check standard). Zn and total Fe in solution were determined using Atomic Absorption Spectroscopy, Teledyne Princeton Instruments, California, USA. Zn has a detection limit of $0.05 \mathrm{mg} / \mathrm{L}$, while Fe has a detection limit of $0.13 \mathrm{mg} / \mathrm{L}$.

\subsection{Methodology}

The methodology for selecting the additive and defining operating conditions for iron removal was structured in three stages. In the first stage, exploratory tests were carried out to select the reagents, considering: iron removal, zinc losses, reagent costs and characteristics of phase separation for an industrial application. In a second stage, experimental treatments were developed for the selected reagents, based on a factorial design, determining the speed separation of phase for a pilot-scale batch operation. In the third stage, the saturation level of the solutions was controlled by oxidation with hydrogen peroxide and potassium permanganate.

\subsubsection{Development of Exploratory Tests}

The exploratory stage aimed to define the operating conditions for applying each of the test reagents: $\mathrm{pH}$ and temperature, to control the level of supersaturation of the solution. Considering previous experiments, removing iron from leaching solutions of zinc concentrates presented difficulties in precipitation due to the formation of colloids. The technological challenge is to avoid the appearance of colloidal solutions that make phase separation difficult and to minimize the formation of amorphous solids that cause zinc co-precipitation. In this first stage, the $\mathrm{pH}$ ranges and operational conditions that influence supersaturation and performance index are defined for each of the reagents used. For all reagents, the $\mathrm{pH}$ range of the iron removal process was identified, considering the transition from the colloidal zone to the colloid-free area as the lower limit and, as the upper limit, the $\mathrm{pH}$ level that generates pulps characterized by difficulties in phase separation.

The experimental treatments for iron precipitation are carried out for each reagent, using $100 \mathrm{~mL}$ of leaching solution from the autoclave reactor. The $\mathrm{pH}$ to define the transition between the colloidal zone and the non-colloidal area is determined by gradually adding each reagent. Once the system has stabilized, the $\mathrm{pH}$ reached is recorded.

The pulp generated is separated by vacuum filtration, obtaining a purified solution and a precipitate. The precipitate is dried in a temperature-controlled oven to avoid the loss of the water of crystallization. Samples of the filtered solution and the solids obtained are taken and sent to the specialized analysis laboratories of the Universidad Católica del Norte. The $\mathrm{Zn}$ and Fe contained in the solutions are analyzed by the Atomic Absorption Spectroscopy technique and the Acid Digestion method, with a detection limit of $0.001 \mathrm{~g} / \mathrm{L}$. Digestion methods are used to reduce interference due to the presence of organic matter and to convert metals to a form that allows analysis. For solids, the techniques of Qemscan and X-ray Diffraction are applied. Once the results of the studies are received, a mass balance is carried out to calculate zinc losses and iron removal.

\subsubsection{Selection of Reagents and Development of Tests Based on a Factorial Experimental Design}

Once the exploratory stage was completed, the most effective reagents were selected, defining as selection criteria: percentage of Fe removal, the concentration of Fe in the purified solution, the portion of Zn losses, advantages, and disadvantages of the volume of solids, the viscosity of the pulp, performance in the filtration stage, and operating costs. For the selected reagents, the rate of phase separation was determined as complementary information to the performance index obtained from the development of the exploratory stage.

To estimate the speed of phase separation, experimental tests were carried out using representative samples as a control strategy. The volume and filtering time data were 
tabulated and plotted to obtain the $\mathrm{t} v / \mathrm{s} v$ curves, which allow calculating the specific resistance of the filter cake. Experiments were programmed to determine the following parameters: mass of the dry and wet cake, the concentration of solids in the influent suspension, the volumetric fraction of liquid in the influent suspension, filtration volume and time, pulp density, and viscosity. The behavior of two reagents were analyzed: slaked lime and sodium carbonate.

Considering the need to obtain information to design a continuous process for the leaching solution, the autoclave outlet conditions were simulated with the inlet temperature to the iron removal unit. The operating levels of the reactor were established by preliminary exploratory tests, considering the dissolution of the reagents and the homogeneity of the residue.

Table 1 shows the detail of the levels considered for each factor analyzed.

Table 1. Levels of influencing factors.

\begin{tabular}{ccccc}
\hline Factors & High Level & Low Level & Number of Levels & Unit \\
\hline pH & 6 & 4 & 3 & - \\
Temperature & 60 & 30 & 2 & ${ }^{\circ} \mathrm{C}$ \\
Stirring & 400 & 300 & 2 & $\mathrm{rpm}$ \\
Time & 20 & 10 & 2 & $\mathrm{~min}$ \\
\hline
\end{tabular}

To analyze the results of the second stage of experimentation, an Analysis of Variance (ANOVA) was carried out to evaluate the effect of the influencing factors on the removal of Fe and $\mathrm{Zn}$ losses, with a significance level of 0.05 (ns). Minitab 18 software was used.

The hypothesis formulated is $\mathrm{Y}=\mathrm{Y}$ ( $\mathrm{pH}$, temperature, stirring, time), $\mathrm{Y}$ represents the percentage of Fe removal and $\mathrm{Zn}$ losses.

For all the influencing factors analyzed and their corresponding interactions; the hypotheses to be tested are:

Hypothesis 0 (H0). $\mu$ factor $=\mu$ error

Hypothesis 1 (H1). $\mu$ factor $\neq$ eerror

In which $\mu$ represents the mean for the response variable. For each of the hypothesis tests, the following decision rule was considered:

If $\mathrm{F}>\mathrm{Fns} \rightarrow$ the null hypothesis is rejected

If $\mathrm{F}<\mathrm{Fns} \rightarrow$ the null hypothesis is accepted

Determining the factors and interactions that significantly influence iron removal and zinc losses provides relevant information to scale up the process at an industrial level.

\subsubsection{Oxidation of Solutions}

Once the reagents that present the best characteristics for the solution purification stage have been selected, a final experimentation stage is carried out to define the type and concentration of oxidant necessary to achieve solutions with Fe concentrations lower than $50 \mathrm{ppm}$, according to the requirements of the $\mathrm{Zn}$ electrowinning process [10].

Iron oxidation was carried out with two types of oxidants: hydrogen peroxide $\left(\mathrm{H}_{2} \mathrm{O}_{2}\right)$ and potassium permanganate $\left(\mathrm{KMnO}_{4}\right)$, for which the corresponding oxidation reactions are presented.

$$
\begin{gathered}
2 \mathrm{Fe}^{2+}+\mathrm{H}_{2} \mathrm{O}_{2}+2 \mathrm{H}^{+} \rightarrow 2 \mathrm{Fe}^{3+}+2 \mathrm{H}_{2} \mathrm{O} \\
5 \mathrm{Fe}^{2+}+\mathrm{MnO}_{4}^{-}+8 \mathrm{H}^{+} \rightarrow 5 \mathrm{Fe}^{3+}+\mathrm{Mn}^{2+}+4 \mathrm{H}_{2} \mathrm{O}
\end{gathered}
$$

For hydrogen peroxide, a solution at $30 \%$ was used with a dosage of: $(0.1 \mathrm{~mL} / 100 \mathrm{~mL}) \mathrm{x}$; with $\mathrm{x}=$ Fe concentration in $\mathrm{g} / \mathrm{L}$.

In the case of potassium permanganate, a $10 \%$ solution was prepared, and the dosage was controlled by measuring ORP and $\mathrm{pH}$. 


\section{Results and Discussions}

\subsection{Characterization}

The zinc concentrate comes from a Bolivian mining company with variable Sphalerite content. Table 2 shows the mineralogical composition of a concentrated sample obtained by Qemscan.

Table 2. Mineralogical characterization of zinc concentrate.

\begin{tabular}{cc}
\hline Component & $\%$ \\
\hline Sphalerite & 75.32 \\
Pyrite & 7.38 \\
Chalcopyrite & 0.16 \\
Arsenopyrite & 0.65 \\
Galena & 2.41 \\
Molybdenite & 0.09 \\
Sulphides & 0.01 \\
Fe-Oxides & 0.08 \\
Quartz & 3.32 \\
Feldspar Group & 0.02 \\
Zn-Sulphate & 2.44 \\
Anglesite & 0.76 \\
Sulphates & 1.32 \\
Native S & 5.33 \\
Others & 0.70 \\
\hline
\end{tabular}

The leaching solutions have $\mathrm{Zn}$ contents between $30 \mathrm{~g} / \mathrm{L}$ and $71 \mathrm{~g} / \mathrm{L}$ and Fe concentrations between $5000 \mathrm{mg} / \mathrm{L}$ and 23,000 mg/L, with Fe total/Zn mass ratios between 0.1 and 0.5 . Table 3 presents the characterization of a solution sample obtained from the concentrate leaching process [2].

Table 3. Characterization of the leach solution sample.

\begin{tabular}{cc}
\hline Element & Concentration $(\mathrm{g} / \mathrm{L})$ \\
\hline $\mathrm{Zn}$ & 53.1 \\
$\mathrm{Fe}$ & 6.8 \\
$\mathrm{H}+$ & 79.8 \\
$\mathrm{Cu}$ & 0.14 \\
$\mathrm{Cd}$ & 0.159 \\
$\mathrm{Co}$ & 0.010 \\
\hline
\end{tabular}

\subsection{Exploration Stage}

For each of the reagents, a set of tests was performed varying the reagent dosage and the operating temperature. The $\mathrm{pH}$ was determined for the minimum level of supersaturation of the solution, ensuring operation in a colloid-free system.

Figure 1 shows the behavior of all the test reagents regarding the transition $\mathrm{pH}$ between the colloidal and non-colloidal zone.

For all the reagents, the $\mathrm{pH}$ range of the iron removal process was identified, considering the transition from the colloidal zone to the colloid-free area as the lower limit and, as the upper limit, the $\mathrm{pH}$ level that generates pulps characterized by difficulties in phase separation. Sodium carbonate presented the narrowest $\mathrm{pH}$ range, 4.8 to 5.5 , while sodium hydroxide had the most comprehensive working range, 2.3 to 6.2.

To analyze the results of the exploratory stage, the percentages of iron removal and zinc losses are considered. A significant challenge is to achieve approximately $20 \%$ of $\mathrm{Zn}$ losses, considering the requirements on an industrial scale. 


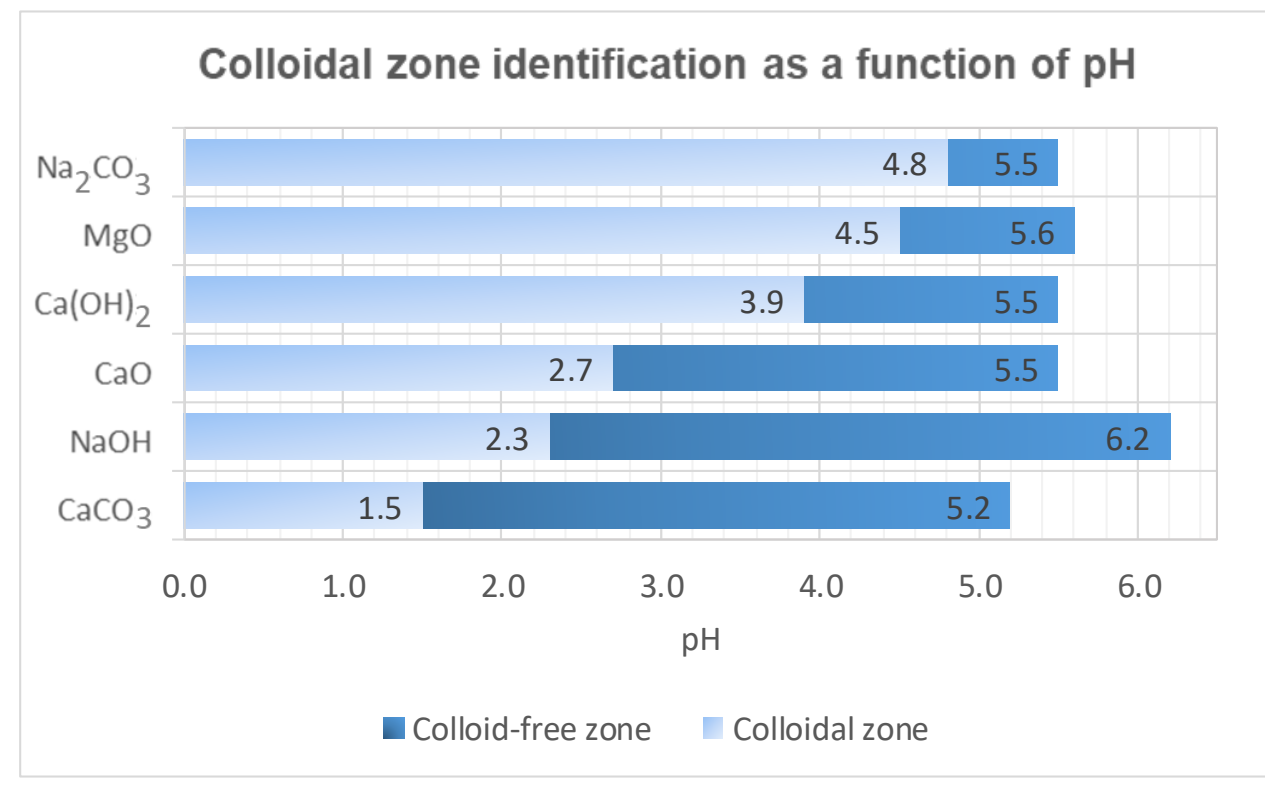

Figure 1. Identification of the colloidal zone for the test reagents.

For $\mathrm{Na}_{2} \mathrm{CO}_{3}, 22$ exploratory tests were carried out up to a $\mathrm{pH}$ value of 5.5 and with variable temperatures between $25^{\circ} \mathrm{C}$ and $60^{\circ} \mathrm{C}$. The leaching solution was used with a $\mathrm{Fe} / \mathrm{Zn}$ mass ratio varying between 0.3 and 0.4 . This reagent shows the disappearance of the colloidal zone at a higher $\mathrm{pH}, 4.8$, and the dosages were $0.205 \mathrm{~g} / \mathrm{mL}$ at $\mathrm{pH} 4.8$ and $0.25 \mathrm{~g} / \mathrm{mL}$ at $\mathrm{pH} 5.5$. The molar ratio $(\mathrm{OH} /$ total $\mathrm{Fe})$ varied between 11 and 15 .

Figure 2 represents the results obtained at $\mathrm{pH}$ between 4.8 and 5.5.

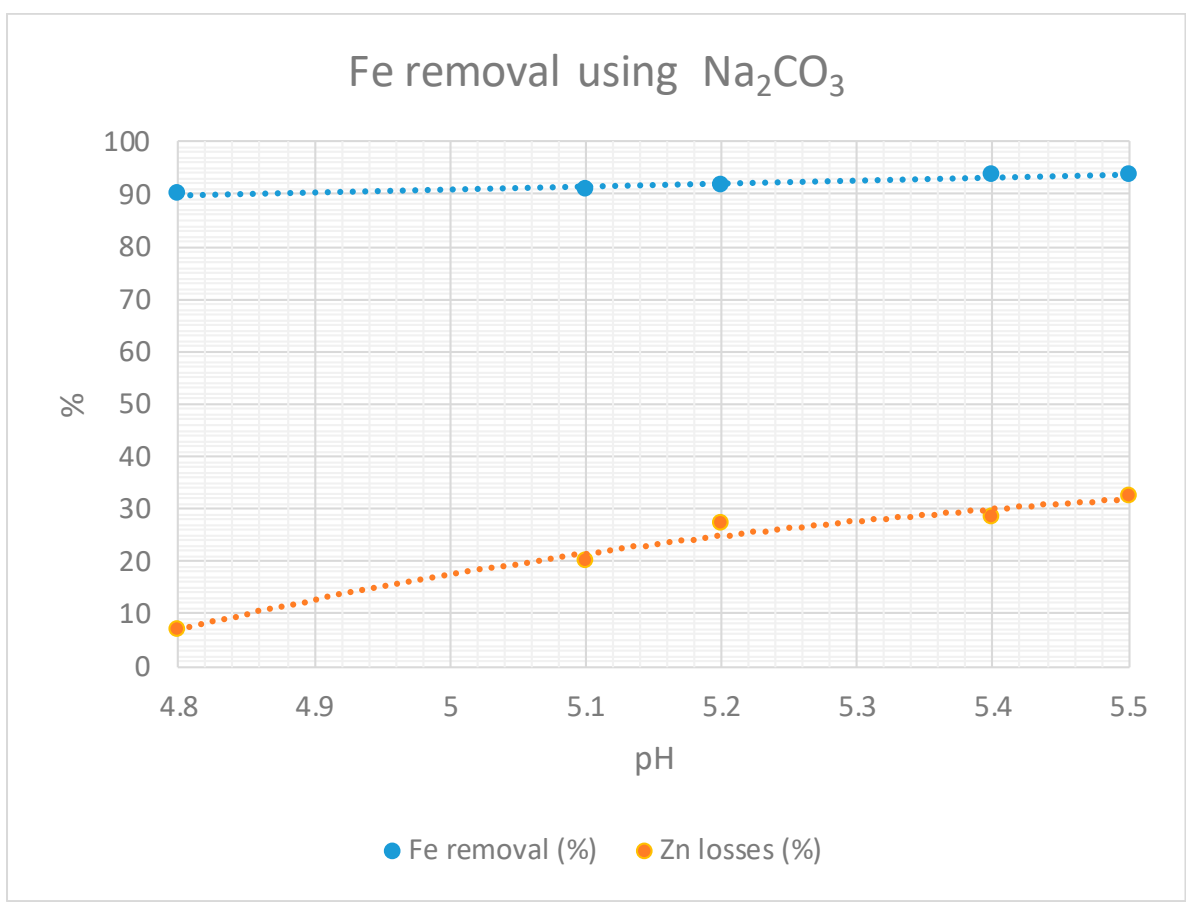

Figure 2. Exploratory test results using $\mathrm{Na}_{2} \mathrm{CO}_{3}$.

According to the results obtained, iron removal and zinc losses increase with $\mathrm{pH}$. Iron removal rises from $90 \%$ to $94 \%$ and zinc losses from $7 \%$ to $33 \%$. The test carried out at $\mathrm{pH} 4.8$ presents the highest performance index showing $90 \%$ iron removal and $7 \%$ zinc loss; it should be noted that the process was carried out at $60{ }^{\circ} \mathrm{C}$, which contributed to 
controlling the level of supersaturation by coagulating the colloidal suspension. The other tests were carried out at an average temperature of $30^{\circ} \mathrm{C}$. For iron removal, there is no significant influence on temperature. Figure 3 shows the XRD for the precipitated solids regarding the solid phase. The sample was reported with a low degree of crystallinity, identifying in the crystalline phase $49.5 \%$ of Zincbloedite $\left(\mathrm{Na}_{2} \mathrm{Zn}\left(\mathrm{SO}_{4}\right)_{2} 4 \mathrm{H}_{2} \mathrm{O}\right), 41.8 \%$ of Tenardite $\left(\mathrm{Na}_{2} \mathrm{SO}_{4}\right)$ and $8.7 \%$ of halite $(\mathrm{NaCl})$; iron could not be identified as it is part of the amorphous solids. The XRD shows the loss of zinc due to the formation of sulphated salts in the working $\mathrm{pH}$ range.

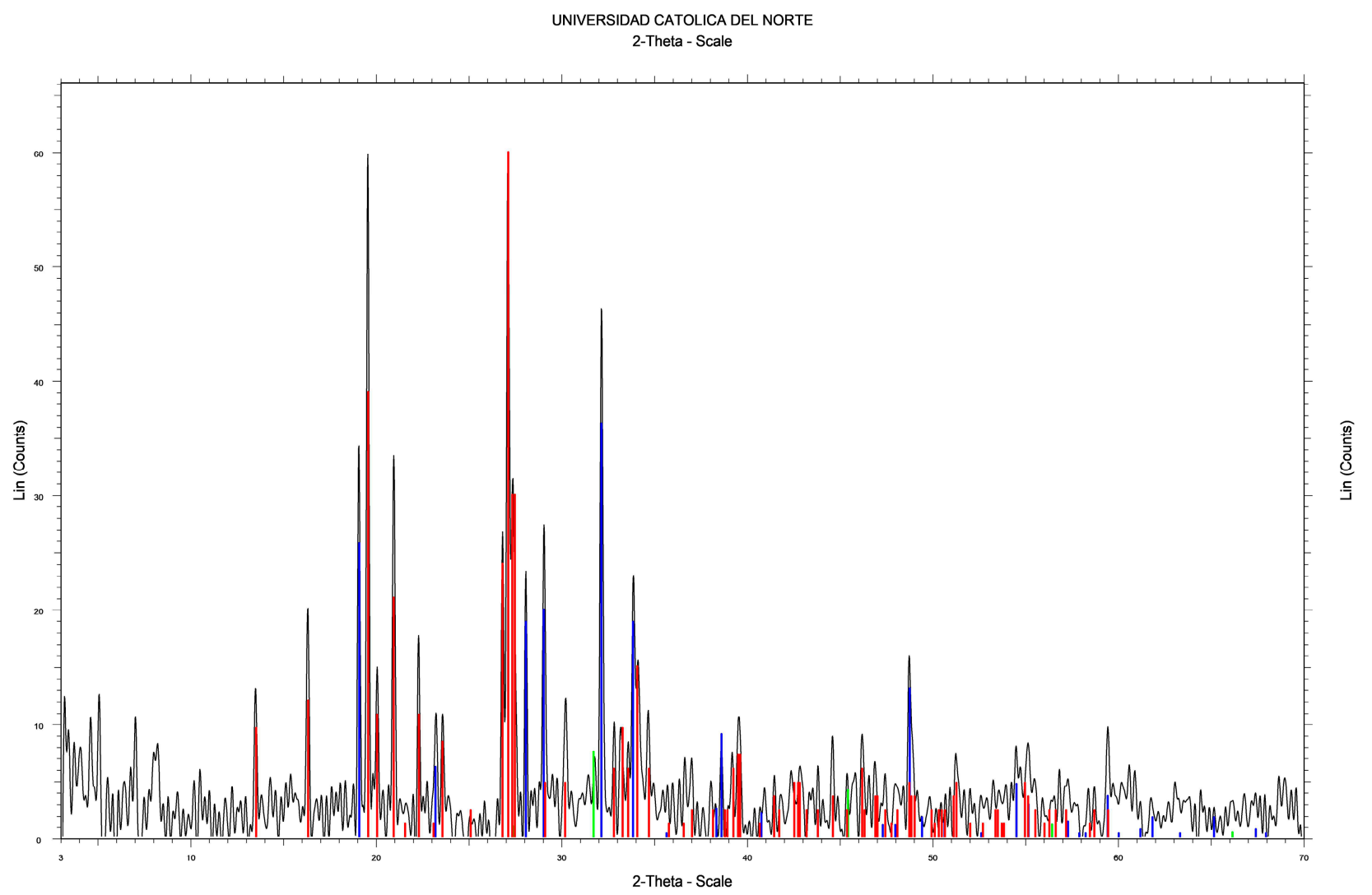

Figure 3. XRD patterns of the solids using $\mathrm{Na}_{2} \mathrm{CO}_{3}$.

Sixteen exploratory tests were carried out for magnesium oxide, using leaching solutions with mass ratios total $\mathrm{Fe} / \mathrm{Zn}$ varying between 0.1 and 0.2 . In this case, the noncolloidal zone is verified from $\mathrm{pH}$ 4.5. The magnesium oxide dosage was $0.075 \mathrm{~g} / \mathrm{mL}$ at $\mathrm{pH} 4.5$ and $0.12 \mathrm{~g} / \mathrm{mL}$ at $\mathrm{pH}$ 5.6. The molar ratio $(\mathrm{OH} /$ total $\mathrm{Fe})$ varied between 24 and 30.

Figure 4 shows the results obtained for the experiments in the $\mathrm{pH}$ range between 4.5 and 5.6.

The percentage of Fe removal and the portion of $\mathrm{Zn}$ losses increases with $\mathrm{pH}$ for $\mathrm{MgO}$. Iron removal varies between $85 \%$ and $92 \%$ and zinc losses are between $12 \%$ and $30 \%$. The control of the level of supersaturation was carried out by keeping the temperature at an average of $52{ }^{\circ} \mathrm{C}$. It was obtained $88 \%$ of iron removal and $22 \%$ of zinc losses; for a pH of 5.2.

The aqueous dissolution of $\mathrm{MgO}$ is a slow process [38], which decreases supersaturation and favors the formation of larger particles and, therefore, a sludge that presents more favorable conditions in the phase separation stage. However, for its industrial application, the consumptions must be considered according to the molar ratio $(\mathrm{OH} / \mathrm{Total} \mathrm{Fe})$ and the operating costs.

In the case of quicklime, 32 exploratory tests were carried out, mainly because of the reagent on changes in $\mathrm{pH}$. The solutions used in the experimentation presented total $\mathrm{Fe} / \mathrm{Zn}$ 
ratios between 0.2 and 0.5 and the temperature varied between $30{ }^{\circ} \mathrm{C}$ and $90{ }^{\circ} \mathrm{C}$. The noncolloidal zone was identified from a $\mathrm{pH}$ equal to 2.7 . The reagent dosage was $0.14 \mathrm{~g} / \mathrm{mL}$ at $\mathrm{pH} 2.7$ and $0.25 \mathrm{~g} / \mathrm{mL}$ at $\mathrm{pH}$ 5.5. The molar ratio $(\mathrm{OH} /$ total Fe) varied between 15 and 29.

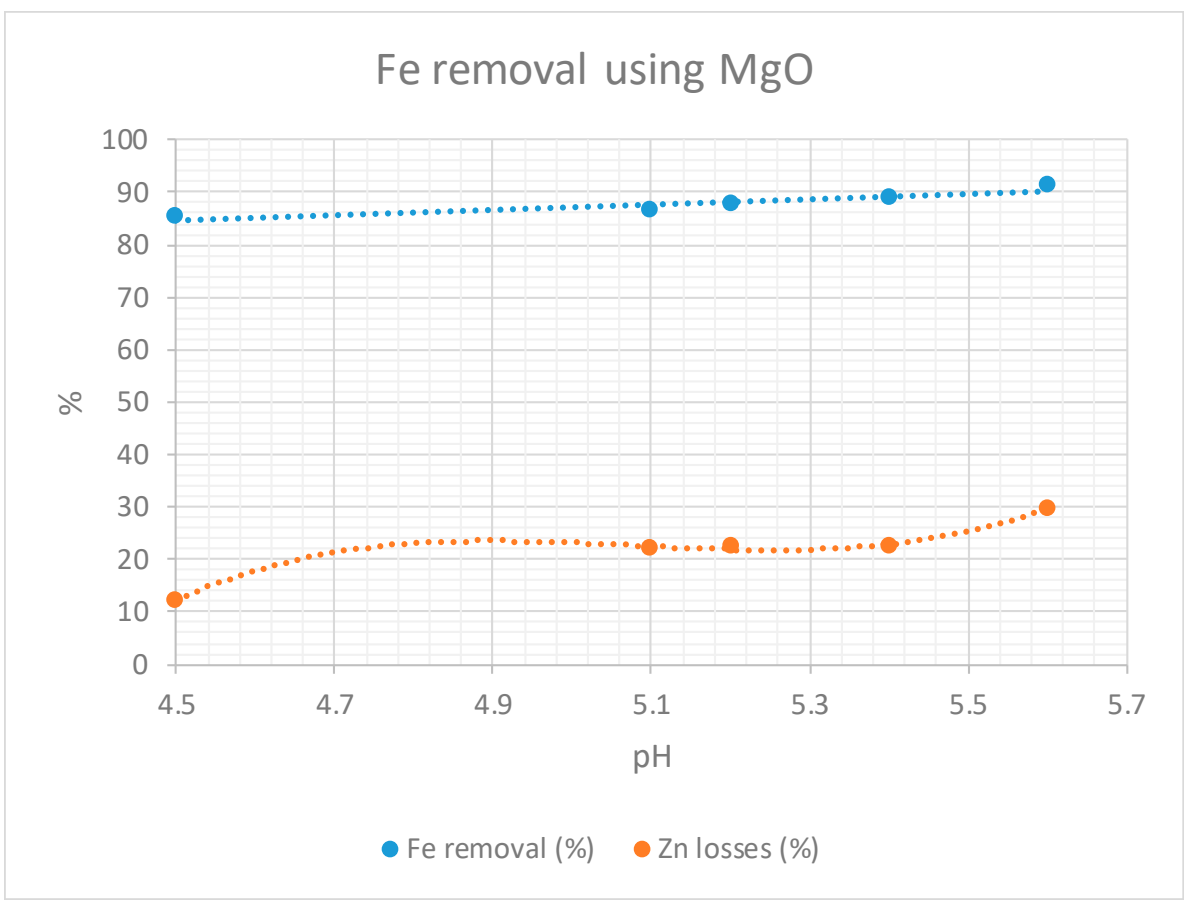

Figure 4. Exploratory test results using MgO.

Figure 5 shows the results obtained for removing iron and zinc losses in the $\mathrm{pH}$ range of 2.7 to 5.5 .

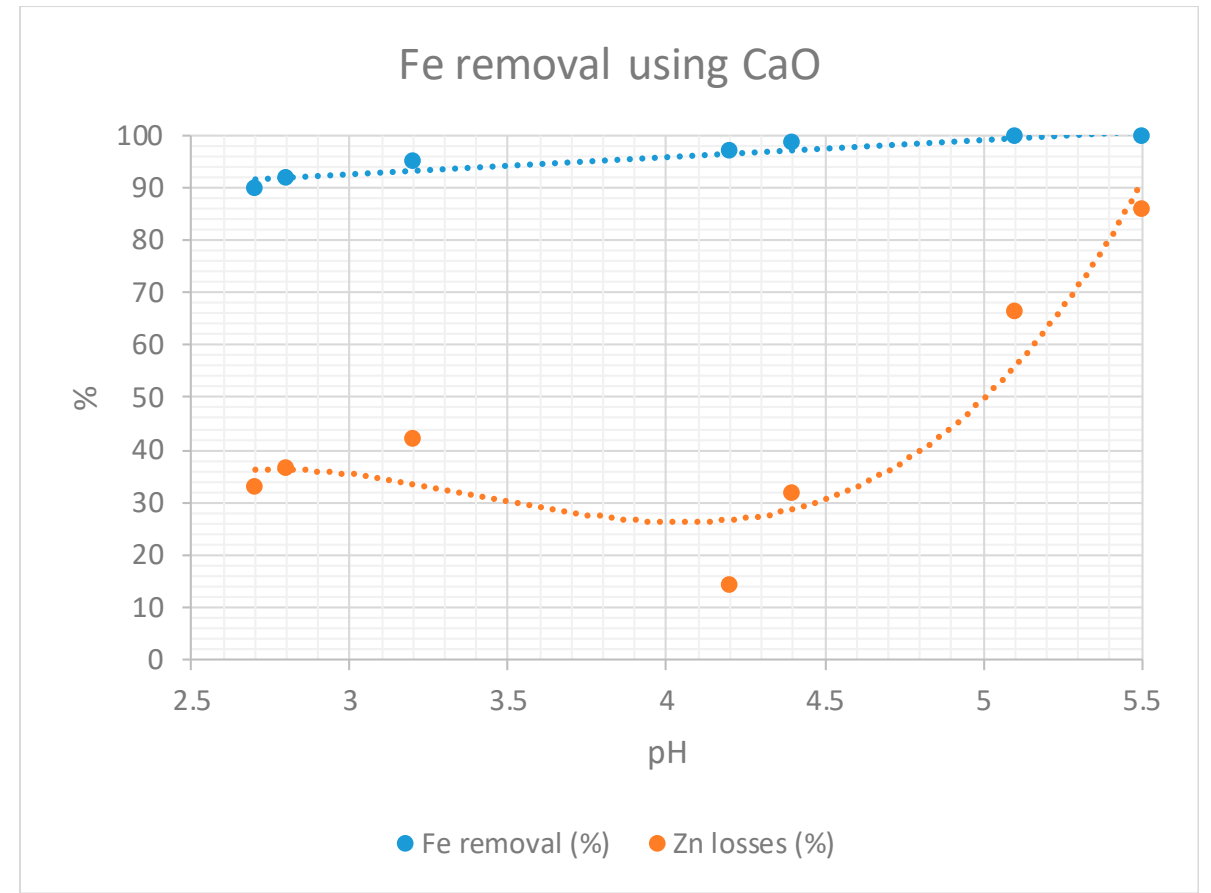

Figure 5. Exploratory test results using $\mathrm{CaO}$.

$\mathrm{CaO}$ presented a good performance for removing iron, but high zinc loses in the precipitated solid. Iron removal increased from $89.7 \%$ at $\mathrm{pH} 2.7$ to $99.5 \%$ at $\mathrm{pH} 5.5$; while 
zinc losses increased from $32.7 \%$ at $\mathrm{pH} 2.7$ to $85.7 \%$ at $\mathrm{pH} 5.5$. For this reagent, the temperature is an influencing factor on the $\mathrm{Zn}$ losses. In particular, the experimentation carried out at a $\mathrm{pH}$ of 4.2 and a temperature of $30{ }^{\circ} \mathrm{C}$ stands out, in which iron removal reached $96.9 \%$ and the loss of zinc was $14 \%$. The highest loss of zinc was obtained for high values of $\mathrm{pH}$ and temperature $\left(\mathrm{pH}=5.5 ; \mathrm{T}=65^{\circ} \mathrm{C}\right)$.

The XRD patterns of the solid, presented in Figure 6, identified the presence of gypsum, Nontronite $\left(\mathrm{Na}_{0.3} \mathrm{Fe}_{2} \mathrm{Si}_{4} \mathrm{O}_{10}(\mathrm{OH})_{2} \cdot \mathrm{nH}_{2} \mathrm{O}\right)$ and Glaucocerinite $\left(\mathrm{Zn}_{1-\mathrm{x}} \mathrm{Al}_{\mathrm{x}}\right)(\mathrm{OH})_{2}\left(\mathrm{SO}_{4}\right)_{\mathrm{x} / 2} \cdot \mathrm{nH}_{2} \mathrm{O}$.

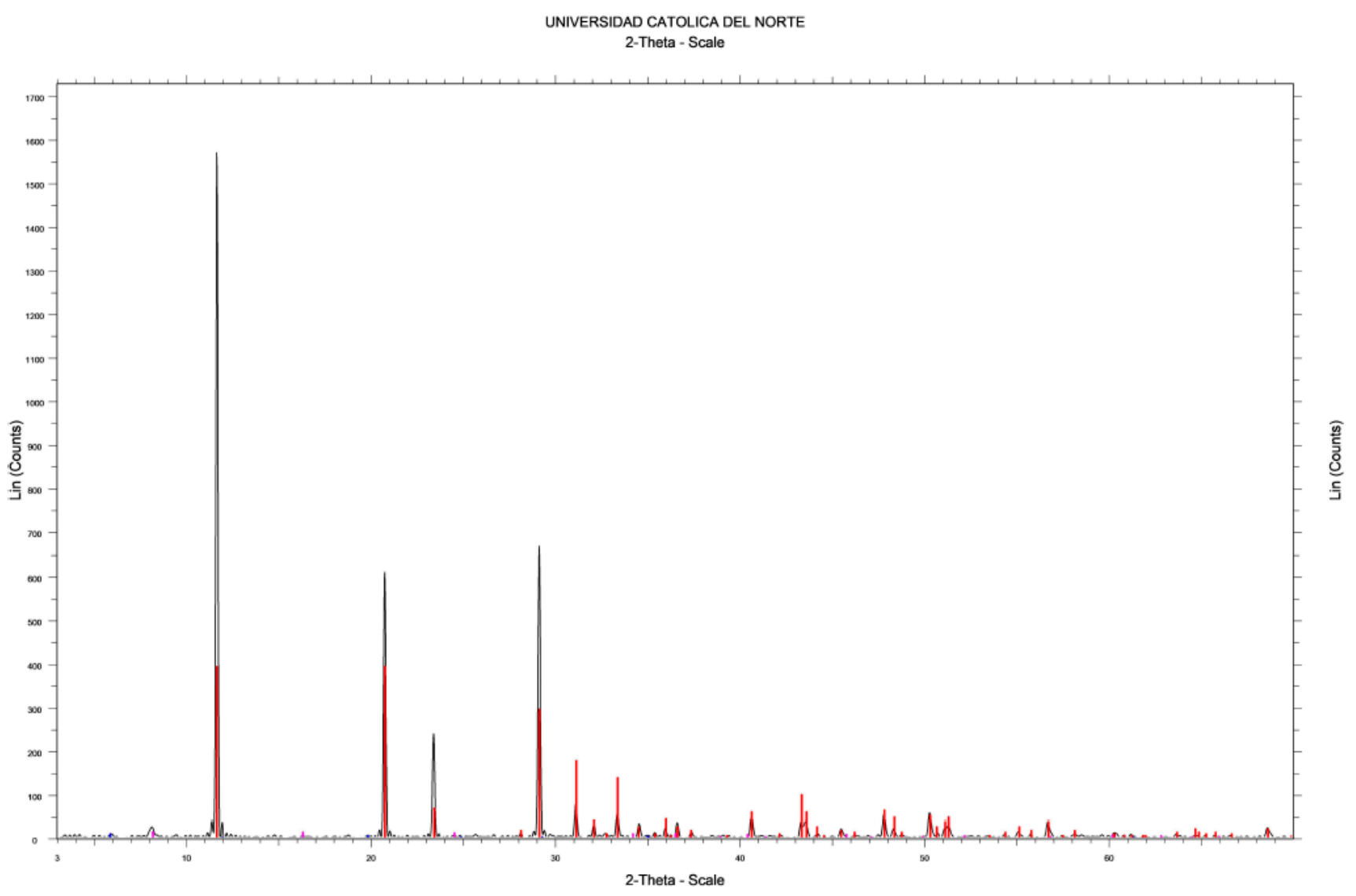

Figure 6. XRD patterns of the solids using $\mathrm{CaO}$.

Additionally, Qemscan (Figure 7) was used to analyze the precipitated solids. Nodular structures formed from a silicate center (quartz grain) were observed. The sulphate layer with high calcium content and variable zinc content seem to be deposited in the different concentric layers.

Considering the experimental evidence related to the analysis of solids, zinc is lost through the formation of hydrated salts and the adsorption mechanism of $\mathrm{Zn}^{2+}$, favored by the increase in temperature. Another aspect to consider is the formation of gypsum in the solution, which generates a large volume of sludge that is difficult to filter. Considering the difficulties in the phase separation stage, tests were carried out with slaked lime, $\mathrm{Ca}(\mathrm{OH})_{2}$, to decrease the pulp's viscosity and increase its homogeneity. Adding lime in lime milk enhances its physical and chemical properties concerning its sedimentation rate and reactivity. 


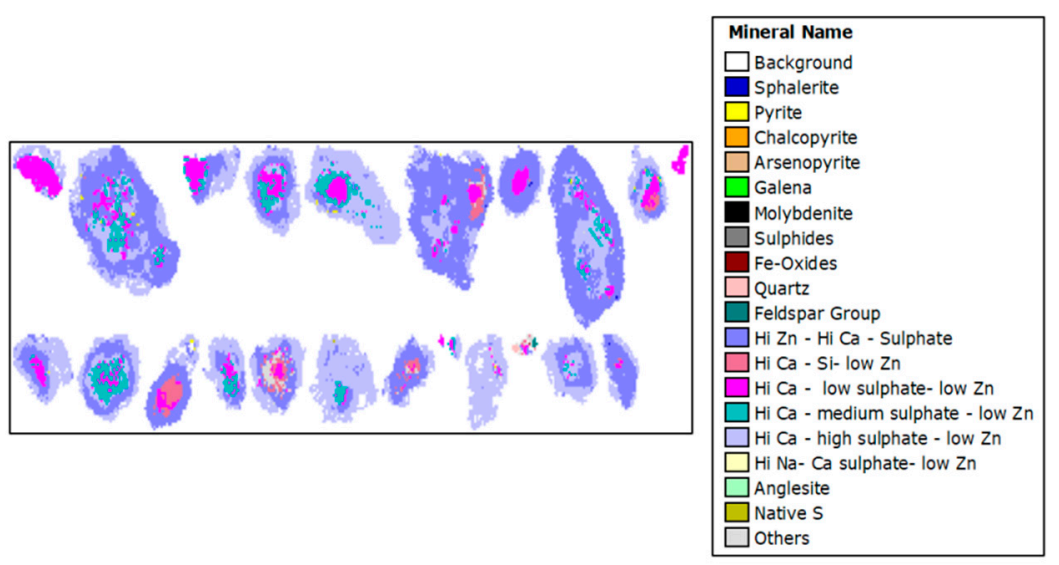

Figure 7. Nodular structures of solids exploratory test using $\mathrm{CaO}$.

The hydration of lime generates slaked lime, which provides the hydroxyl ions for the precipitation of the solid; in addition, gypsum is produced, according to the reactions presented below.

$$
\begin{aligned}
\mathrm{CaO}+\mathrm{H}_{2} \mathrm{O} & \rightarrow \mathrm{Ca}(\mathrm{OH})_{2} \\
\mathrm{Fe}_{2}\left(\mathrm{SO}_{4}\right)_{3}+3 \mathrm{Ca}(\mathrm{OH})_{2}+6 \mathrm{H}_{2} \mathrm{O} & \rightarrow 2 \mathrm{Fe}(\mathrm{OH})_{3}+3 \mathrm{CaSO}_{4} \cdot 2 \mathrm{H}_{2} \mathrm{O}
\end{aligned}
$$

Among the essential parameters in the preparation of the slaked lime are the water/lime ratio and the hydration temperature; to determine the appropriate balance, 20 tests were carried out with different values of the water/lime ratio and different temperatures. The best results were obtained for a water/lime ratio of $2.5 \mathrm{~mL} / \mathrm{g}$. The temperature varied between $55^{\circ} \mathrm{C}$ and $70{ }^{\circ} \mathrm{C}$.

Figure 8 shows the results obtained using lime milk with a dosage of $2.5 \mathrm{~mL}$ water $/ \mathrm{g}$ of lime. The leaching solutions' $\mathrm{Fe} / \mathrm{Zn}$ mass ratio varied between 0.1 and 0.3 and the $\mathrm{pH}$ between 3.9 and 5.5 .

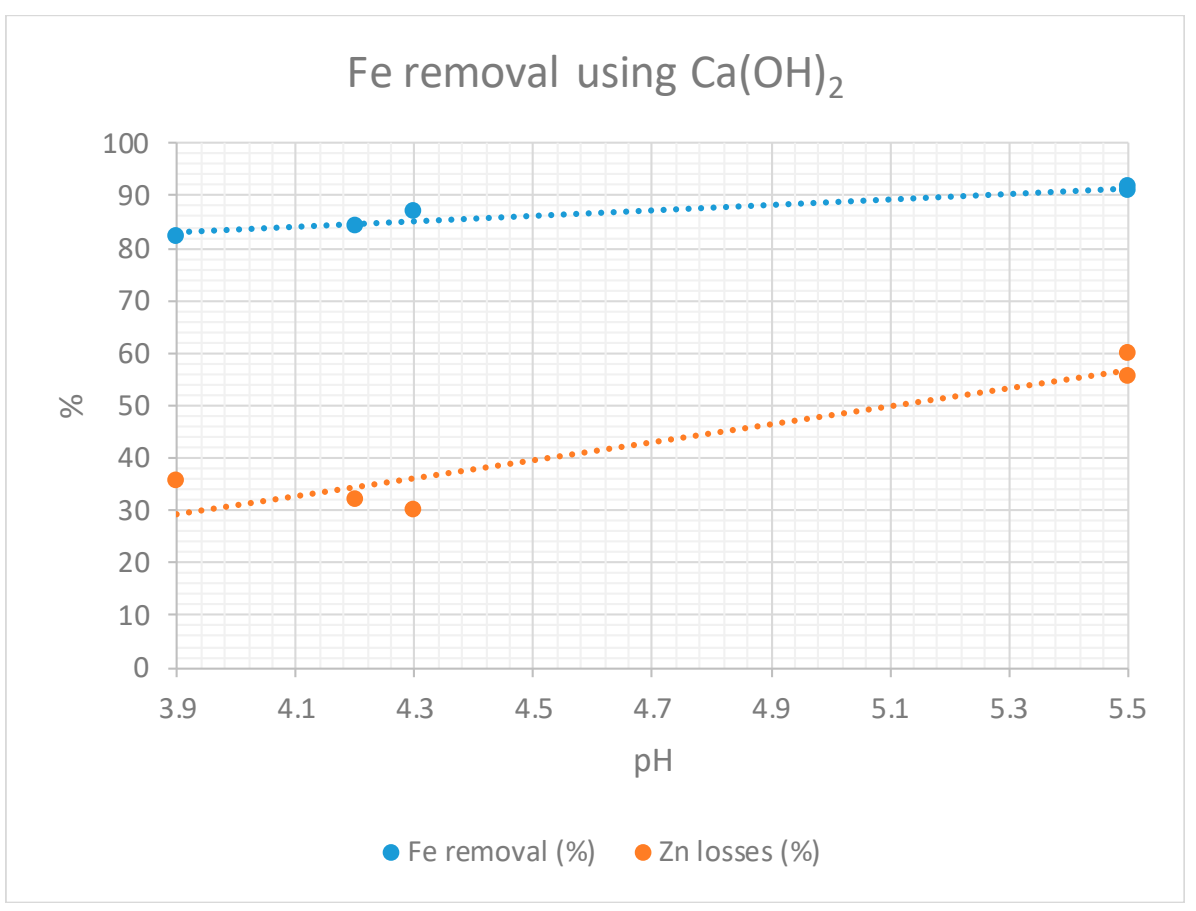

Figure 8. Exploratory test results using $\mathrm{Ca}(\mathrm{OH})_{2}$.

Iron removal, using slaked lime, increased from $82.1 \%$ at $\mathrm{pH} 3.9$ to $91.6 \%$ at $\mathrm{pH} 5.5$. The zinc losses ranged from $30.1 \%$ at $\mathrm{pH} 4.3$ and temperature $55^{\circ} \mathrm{C}$; up to $60.1 \%$ at $\mathrm{pH}$ 
5.5 and temperature $70{ }^{\circ} \mathrm{C}$. Temperature is not an influencing factor for iron removal, but it does affect $\mathrm{Zn}$ losses, which increase with temperature. It was achieved at $\mathrm{pH} 4.3$ and temperature $55{ }^{\circ} \mathrm{C}$, with $87 \%$ iron removal and $30 \%$ zinc losses. Although milk of lime presents favorable conditions for phase separation and low operating costs, it is necessary to reduce zinc losses.

The XRD patterns of the solids, presented in Figure 9, identified gypsum $\left(\mathrm{CaSO}_{4} \cdot 2 \mathrm{H}_{2} \mathrm{O}\right)$, quartz $\left(\mathrm{SiO}_{2}\right)$ and Natroglaucocerinite $\left(\left[\mathrm{Zn}_{5} \mathrm{Al}_{3}(\mathrm{OH})_{16}\right]\left(\mathrm{SO}_{4}\right)_{1.5} \mathrm{Na}_{1.5}\left(\mathrm{SO}_{4}\right)_{0.75} \cdot 6 \mathrm{H}_{2} \mathrm{O}\right)$.

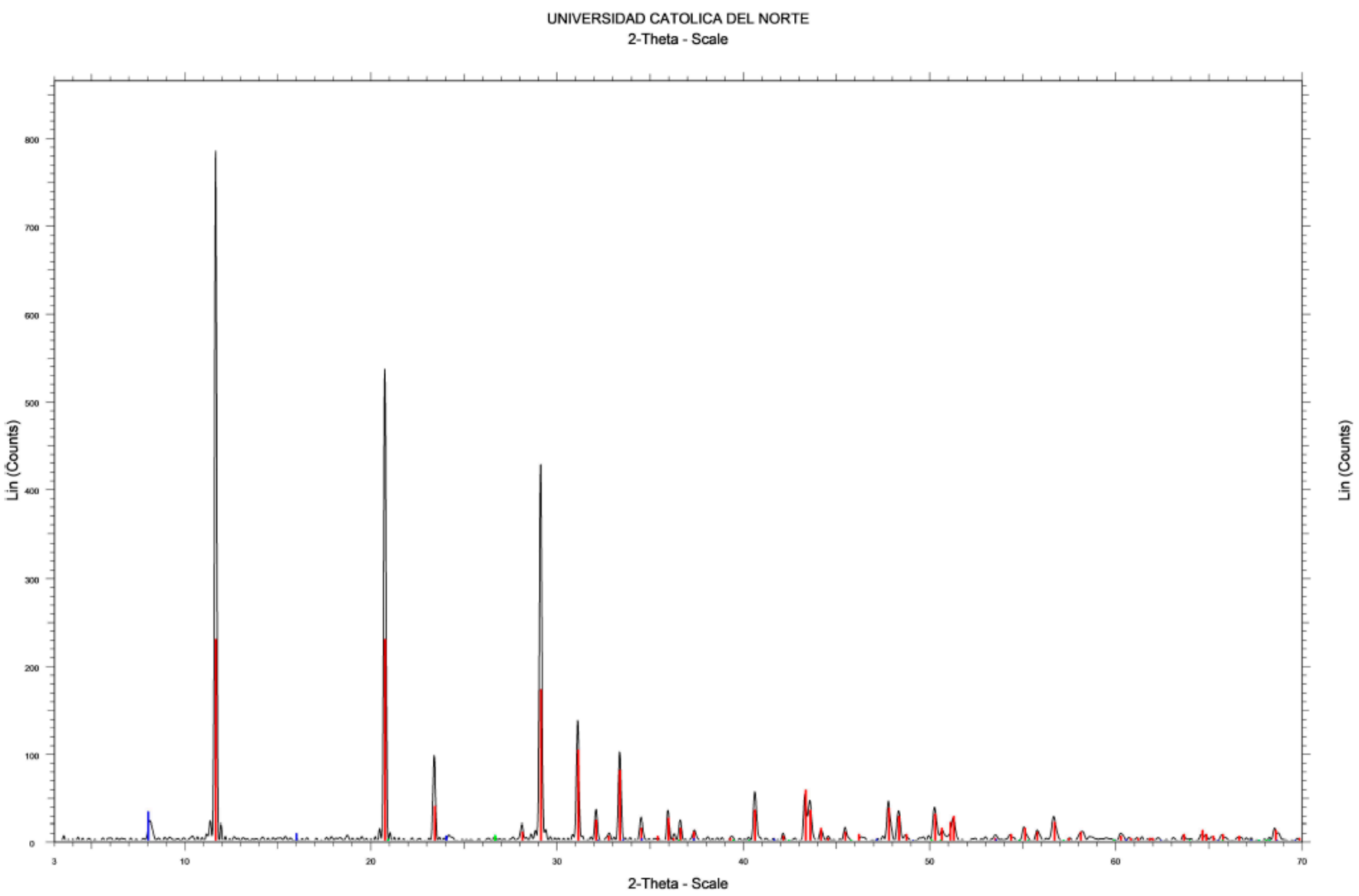

Figure 9. XRD patterns of the solids using $\mathrm{Ca}(\mathrm{OH})_{2}$.

Qemscan was also used for solids analysis. Sulfates with varying zinc contents were identified in the sample. Still unlike solids precipitated with lime, it did not present nodular structures, presenting a more sodic-calcic composition in the sulfates. For $\mathrm{NaOH}$, 12 exploratory tests were carried out, applying the reagent with a concentration of $10 \mathrm{M}$ and with $\mathrm{Fe} / \mathrm{Zn}$ ratios varying between 0.2 and 0.3 . In this case, the $\mathrm{pH}$ range in which the experimentation was carried out was defined between 2.3 and 6.2, according to the identification of the non-colloidal zone. The temperature varied between $40{ }^{\circ} \mathrm{C}$ and $105^{\circ} \mathrm{C}$ and the ratio $(\mathrm{OH} /$ total $\mathrm{Fe})$ was between 17 and 28 .

The results obtained are presented in Figure 10.

According to what is observed in Figure $10, \mathrm{NaOH}$ presented a poor performance in iron removal, which increased from $60.7 \%$ at $\mathrm{pH} 2.3$ to $99 \%$ at $\mathrm{pH} 6.2 .78 \%$ removal was obtained, on average, in a wide $\mathrm{pH}$ range (2.3 to 6.2 ). Zinc losses varied between $14 \%$ and $59 \%$; the increase of zinc losses as a function of $\mathrm{pH}$ is higher than the rate increase of iron removal. For this reagent, the loss of $\mathrm{Zn}$ decreases with increasing temperature, which contributes to controlling the supersaturation level. Considering both Fe removal and $\mathrm{Zn}$ losses, the best result was obtained at a $\mathrm{pH}$ of 3.3 , for which $70 \% \mathrm{Fe}$ removal and $14.5 \% \mathrm{Zn}$ 
losses were achieved, at a temperature of $105^{\circ} \mathrm{C}$. Difficulties arose in the filtration of the precipitate, which its low crystallinity can explain.

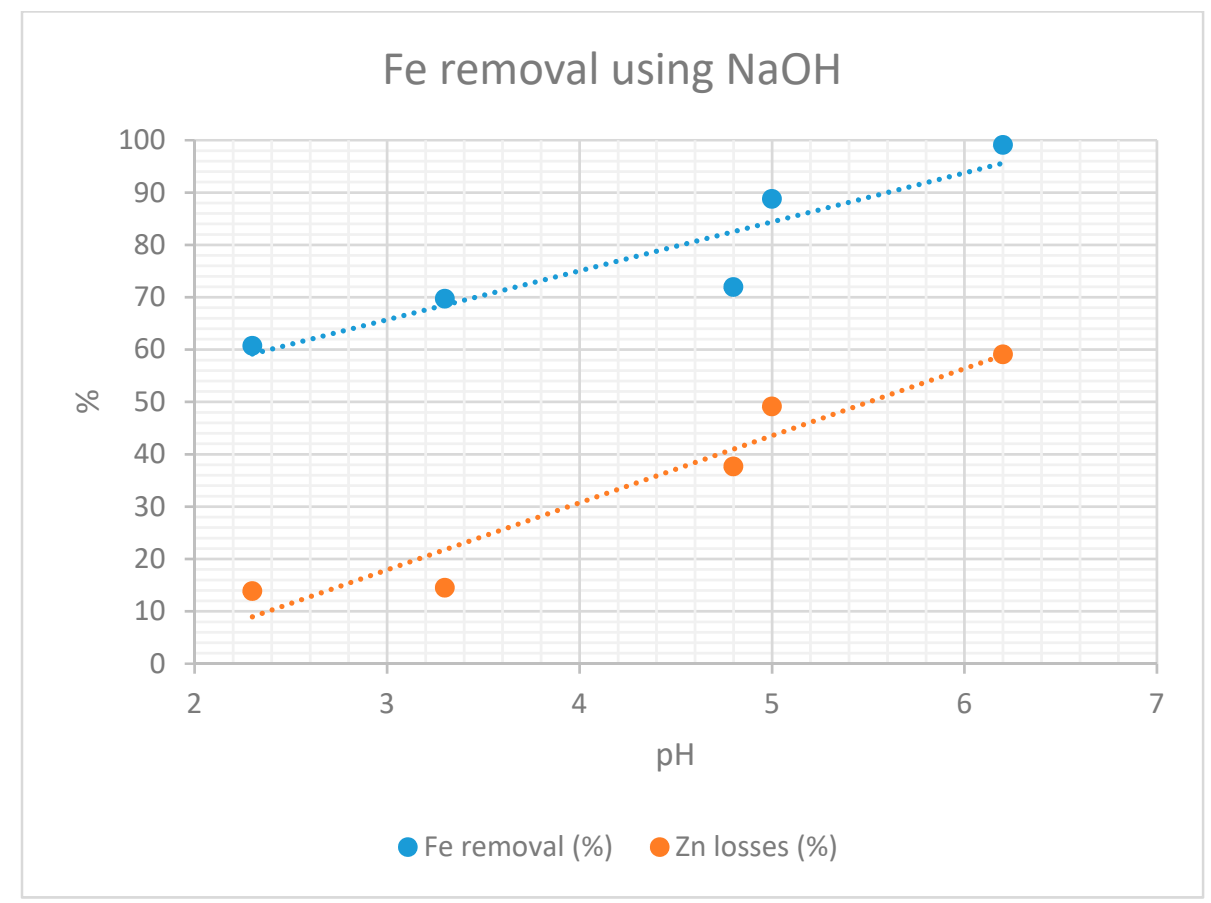

Figure 10. Exploratory test results using $\mathrm{NaOH}$.

For calcium carbonate, unlike other reagents, only six laboratory tests were performed since it presented difficulties in homogenizing the solution and high pulp viscosity (the reagent was added as a solid at $98 \%$ purity). The treated solutions were characterized by a $\mathrm{Fe} / \mathrm{Zn}$ ratio varying between 0.2 and 0.3 ; the temperature of the experimentation was $25^{\circ} \mathrm{C}$ and the $\mathrm{pH}$ varied between 1.5 and 5.2. The reagent dosage ranged between $0.146 \mathrm{~g} / \mathrm{mL}$ and $0.423 \mathrm{~g} / \mathrm{mL}$ and the ratio $(\mathrm{OH} /$ total $\mathrm{Fe})$ was between 15 and 38 .

The experimental results are presented in Figure 11.

The trends of increasing iron removal and zinc losses with increasing $\mathrm{pH}$ are maintained for calcium carbonate. However, for low $\mathrm{pH}$ values (1.5-2.5), iron removal does not exceed $35 \%$. For zinc losses, these vary from $8.7 \%$ at $\mathrm{pH} 1.5$ to $20.4 \%$ at $\mathrm{pH} 5.2$. The results achieved at $\mathrm{pH} 5$ should be noted, in which $87 \%$ iron removal and $15.5 \%$ zinc losses are reached. For this reagent, the problems associated with the formation of gypsum in high-density pulps stand out. Wang et al. [39] used mechanically activated $\mathrm{CaCO}_{3}$, which favored the increase of its solubility and reactivity.

Additionally, in the exploratory stage, tests were carried out using reagent mixtures. In general terms, good results were not achieved. The lime/soda mixture stood out in a ratio of $0.25 / 0.75$, in which a $90 \%$ removal of Fe and $28 \%$ loss of $\mathrm{Zn}$ was achieved at a $\mathrm{pH}$ of 2.7 and a temperature of $60^{\circ} \mathrm{C}$. With this mixture, the viscosity of the pulp generated is reduced, favoring the phase separation stage. 


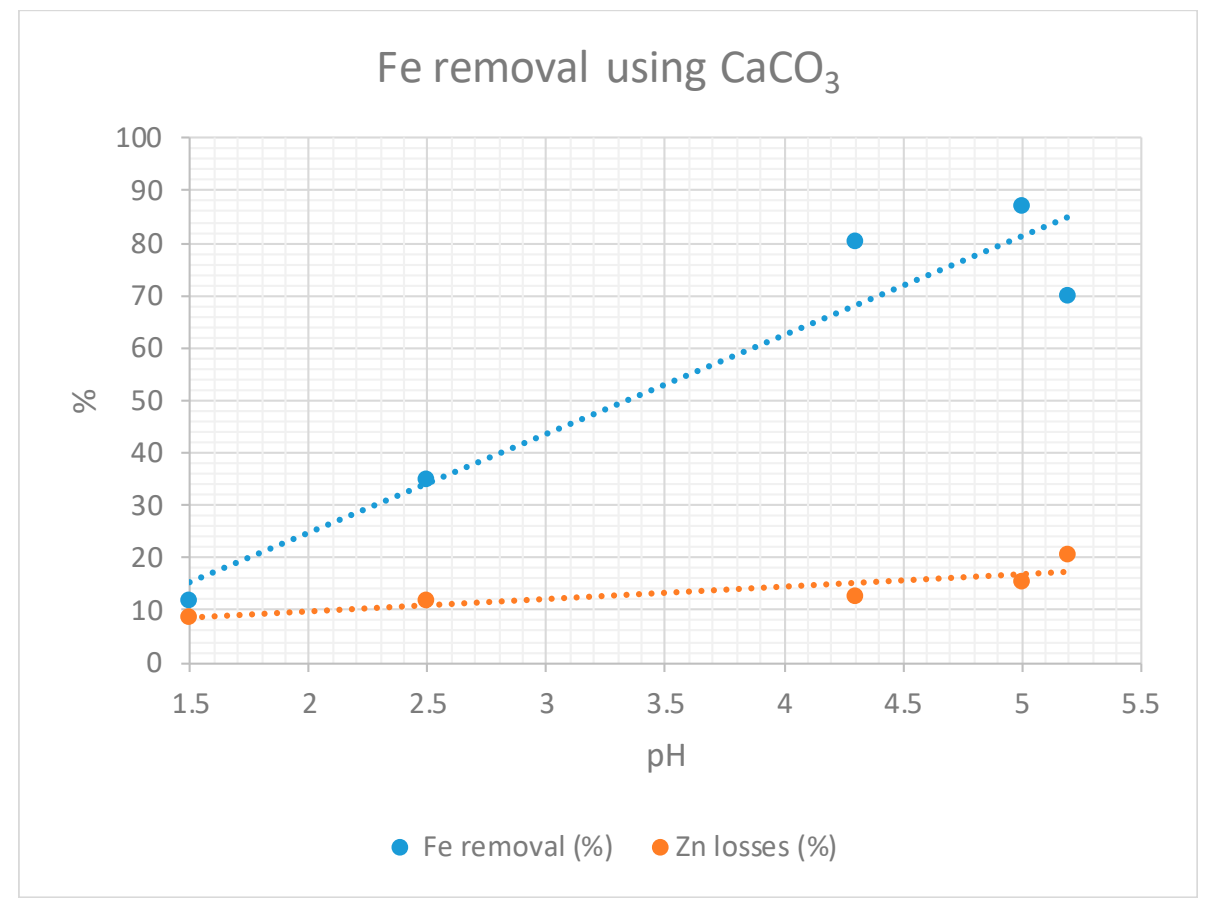

Figure 11. Exploratory test results using $\mathrm{CaCO}_{3}$.

3.3. Selection of Reagents and Development of Factorial Experimental Design-Based Treatments Figure 12 shows the best results obtained for the exploratory tests carried out.

\section{Exploratory test}

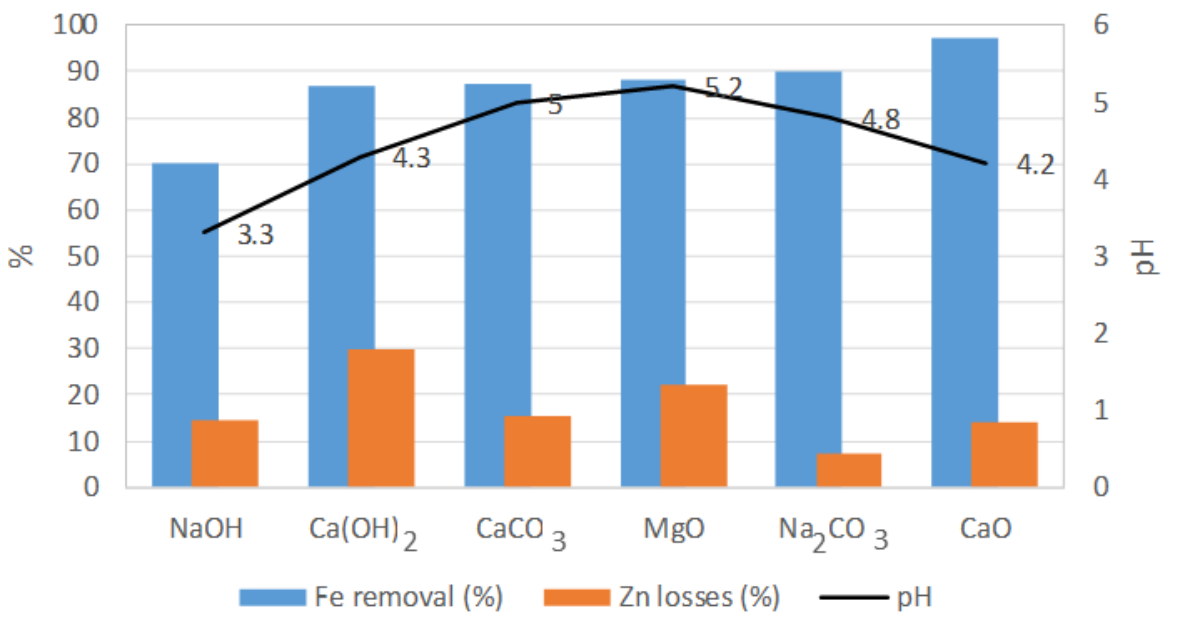

Figure 12. Exploration test results summary.

For the reagents used in the exploratory tests, the $\mathrm{pH}$ levels were determined to control the supersaturation of the solutions (Figure 1). Regarding iron removal and zinc losses, $\mathrm{Na}_{2} \mathrm{CO}_{3}$ and $\mathrm{CaO}$ show the best results at $\mathrm{pH} 4.8$ and 4.2 , respectively (Figure 12). Slaked lime stands out for presenting favorable conditions in the phase separation stage; Furthermore, it is the reagent that shows a lower level of supersaturation $(\mathrm{OH} / \mathrm{Fe}=7)$.

Table 4 summarizes each of the reagents used in the exploratory tests, considering the defined selection criteria. 
Table 4. Summary of exploratory tests results.

\begin{tabular}{|c|c|c|c|}
\hline Reagent & Advantages & Disadvantages & Performance Indices \\
\hline $\mathrm{CaO}$ & $\begin{array}{ll}\text { - } & \text { High percentage of removal } \\
\text { of Fe } \\
-\quad \text { Low percentage of } \mathrm{Zn} \text { losses } \\
-\quad \text { Low cost } \\
-\quad \text { Outstanding performance in } \\
\text { the removal of Fe }\end{array}$ & $\begin{array}{l}\text { - Chemical instability of the } \\
\text { precipitate } \\
\text { - Formation of large volumes } \\
\text { of sludge } \\
\text { - Difficulties in phase } \\
\text { separation }\end{array}$ & $\begin{array}{l}\text { - } \\
\text { losses at } \mathrm{pH}=4.2,30^{\circ} \mathrm{C}, \\
\text { Fe } / \mathrm{Zn}=0.4 \\
\text { - } \\
\text { Residual Fe concentration: } \\
427 \mathrm{ppm} \\
\text { - } \quad \text { Cost: US } \$ 2.6 / \text { ton }\end{array}$ \\
\hline $\mathrm{Na}_{2} \mathrm{CO}_{3}$ & $\begin{array}{ll}\text { - } & \text { High percentage of removal } \\
\text { of Fe } \\
\text { - } \quad \text { Low percentage of } \mathrm{Zn} \text { losses, } \\
\text { outstanding performance } \\
\text { - } \quad \text { Low viscosity } \\
\text { - } \quad \text { Low percentage of solids }\end{array}$ & $\begin{array}{l}\text { - Difficulties in phase } \\
\text { separation } \\
\text { - } \quad \text { High cost } \\
\text { - } \quad \text { The reagent has the highest } \\
\text { transition } \mathrm{pH} \text { value to the } \\
\text { non-colloidal zone, } 4.8\end{array}$ & $\begin{array}{l}\text { - } 90 \% \text { removal of Fe and } 7.1 \% \\
\text { loss of } \mathrm{Zn} \text { at } \mathrm{pH}=4.8,60^{\circ} \mathrm{C}, \\
\mathrm{Fe} / \mathrm{Zn}=0.4 \\
\text { - } \\
\text { Residual Fe concentration: } \\
1890 \mathrm{ppm} \\
\text { - } \quad \text { Cost: US } \$ 285 / \text { ton }\end{array}$ \\
\hline $\mathrm{MgO}$ & $\begin{array}{l}\text { - The aqueous dissolution of } \\
\text { MgO is a slow process, and } \\
\text { this generates a greater } \\
\text { control in the level of } \\
\text { supersaturation } \\
\text { - Low viscosity } \\
\text { - } \quad \text { Low percentage of solids }\end{array}$ & $\begin{array}{ll}\text { - } & \text { High price } \\
\text { - } & \text { The reagent has a high } \\
\text { transition } \mathrm{pH} \text { value to the } \\
\text { non-colloidal zone, } 4.5\end{array}$ & $\begin{array}{l}\text { - } \\
\text { losses at } \mathrm{pH}=5.2,50{ }^{\circ} \mathrm{C}, \\
\text { Fe } / \mathrm{Zn}=0.2 \\
\text { - } \quad \text { Residual Fe concentration: } \\
\text { 1023 ppm } \\
\text { - Cost: US\$ } 118 / \text { ton }\end{array}$ \\
\hline $\mathrm{CaCO}_{3}$ & $\begin{array}{l}\text { - Outstanding performance } \\
\text { regarding the reduction of } \\
\text { zinc losses }\end{array}$ & $\begin{array}{ll}\text { - } & \text { High pulp viscosity } \\
\text { - } & \text { Difficulties in phase } \\
& \text { separation } \\
\text { - } & \text { High cost }\end{array}$ & $\begin{array}{l}\text { - } \\
\text { losses at } \mathrm{pH}=5.25^{\circ} \mathrm{C}, \\
\text { Fe } / \mathrm{Zn}=0.3 \\
\text { - } \quad \text { Residual Fe concentration: } \\
1660 \mathrm{ppm} \\
\text { - } \quad \text { Cost: US } \$ 100 / \text { ton }\end{array}$ \\
\hline $\mathrm{Ca}(\mathrm{OH})_{2}$ & $\begin{array}{l}\text { - Generation of sludge with } \\
\text { favorable characteristics in } \\
\text { phase separation } \\
\text { - The energy generated by the } \\
\text { hydration reaction can be } \\
\text { used } \\
\text { - Low cost }\end{array}$ & High percentage of solids & 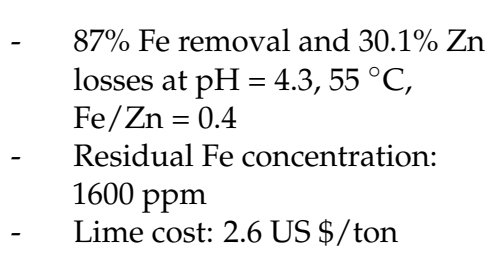 \\
\hline $\mathrm{NaOH}$ & $\begin{array}{ll}\text { - } & \text { Low percentage of solids } \\
\text { - } & \text { Low viscosity }\end{array}$ & $\begin{array}{ll}\text { - } & \text { Low percentage of removal of } \\
\text { - } & \text { Fe } \\
& \text { High concentration of } \\
\text { - } & \text { residual Fe } \\
\text { - } & \text { High cost } \\
- & \text { Difficulties filtration }\end{array}$ & 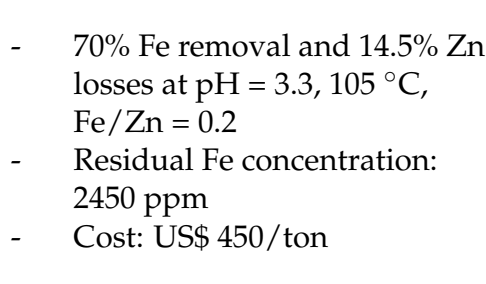 \\
\hline $\mathrm{Cal}+\mathrm{NaOH}$ & $\begin{array}{l}\text { - Good performance in iron } \\
\text { removal }\end{array}$ & $\begin{array}{ll}\text { - } & \text { High percentage of solids } \\
\text { - } & \text { High cost }\end{array}$ & $\begin{array}{l}\text { - } 90 \% \text { Fe removal and } 28.4 \% \mathrm{Zn} \\
\text { losses at } \mathrm{pH}=2.7,60^{\circ} \mathrm{C}, \\
\mathrm{Fe} / \mathrm{Zn}=0.2 \\
\text { Residual Fe concentration: } \\
1640 \mathrm{ppm}\end{array}$ \\
\hline
\end{tabular}

The selected reagents were: $\mathrm{CaO}$ in slaked lime and sodium carbonate. Lime has good performance for iron removal. However, it has difficulties in the phase separation stage; therefore, it was decided to use $\mathrm{Ca}(\mathrm{OH})_{2}$, considering the low operating costs. In the case of $\mathrm{Na}_{2} \mathrm{CO}_{3}$, this is a reagent that can efficiently remove $\mathrm{Fe}$, controlling zinc losses. In 
addition, these reagents presented the lowest levels of supersaturation, measured through the ratio $(\mathrm{OH} / \mathrm{Fe})$, which, for the selected tests, was equal to 7 for slaked lime and 11 for sodium carbonate.

To provide information to carry out pilot-scale tests, experimental treatments were developed based on a factorial design, using the selected reagents. The factors analyzed were $\mathrm{pH}$, temperature, stirring speed, and reaction time at the levels presented in Table 1. In the case of $\mathrm{Ca}(\mathrm{OH})_{2}, 16$ treatments were carried out, with all the factors at 2 levels and with 1 replication. The Analysis of Variance, with a significance level of 5\%, identified $\mathrm{pH}$ as a significantly influential variable on iron removal, with an F value of 198.9 and a $p$-value of 0.045 . In relation to zinc losses, they are significantly influenced by $\mathrm{pH}$ $(\mathrm{F}=3310, p$-value $=0.011)$; the temperature-stirring interaction $(\mathrm{F}=166.7, p$-value $=0.049)$; the stirring-time interaction $(\mathrm{F}=289.9, p$-value $=0.037)$ and the temperature-stirring-pH interaction $(\mathrm{F}=399.4, p$-value $=0.032)$.

Iron removal is fundamentally regulated by $\mathrm{pH}$; however, to control the loss of zinc, the $\mathrm{pH}$, and the interactions between the different factors of the experimentation must be considered. Both iron removal and zinc losses increase with $\mathrm{pH}$. Zinc can be lost by adsorption or the formation of mixed crystals, as evidenced by the analysis of solids through XRD (Figure 9) and Qemscan in which sulfates with varying zinc contents were identified with a sodium-calcium composition.

The increase in temperature can contribute to adsorption losses, but it also influences the dehydration of solids, generating a denser mass and a lower specific surface area for adsorption. The stirring speed contributes to reducing the number of $\mathrm{Zn}^{2+}$ ions adsorbed. The formation of mixed crystals is inherent in this solution that constitutes complex mixtures of ions. Their precipitation depends on solubility, which is affected by temperature, stirring, $\mathrm{pH}$ and time. In the case of losses due to occlusion and mechanical entrapment, these occur during the precipitate formation. In this sense, it is necessary to control the speed of its construction and keep the level of supersaturation low.

Figures 13 and 14 present box and whisker plots that show the effect of $\mathrm{pH}$ and temperature on iron removal and zinc losses, using $\mathrm{Ca}(\mathrm{OH})_{2}$. To have more information, tests with $\mathrm{pH}=5$ were added to the data used for the analysis of variance, keeping the other variables at the defined levels: temperature $30^{\circ} \mathrm{C}$ and $60^{\circ} \mathrm{C}$; stirring speed $300 \mathrm{rpm}$ and $400 \mathrm{rpm}$; time $10 \mathrm{~min}$ and $20 \mathrm{~min}$. The results of 24 experimental treatments are presented.

\section{$\mathrm{pH}$ effect on the purification of solutions using $\mathrm{Ca}(\mathrm{OH})_{2}$.}

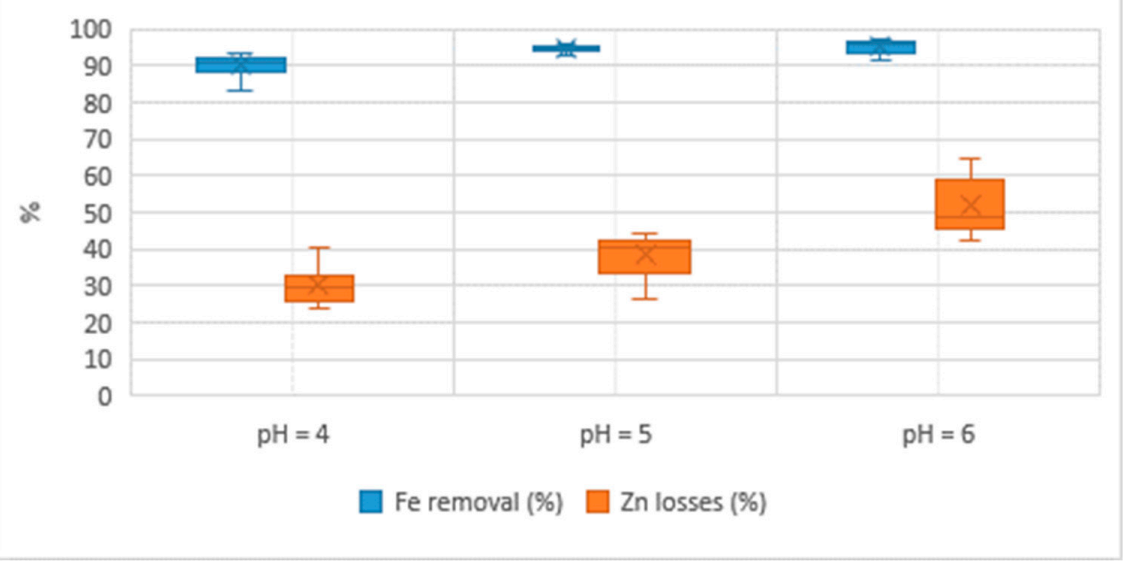

Figure 13. $\mathrm{pH}$ effect on the purification of solutions using $\mathrm{Ca}(\mathrm{OH})_{2}$.

The trends show the effect of $\mathrm{pH}$ on the removal of Fe and zinc loss, with a higher incidence of zinc losses. 


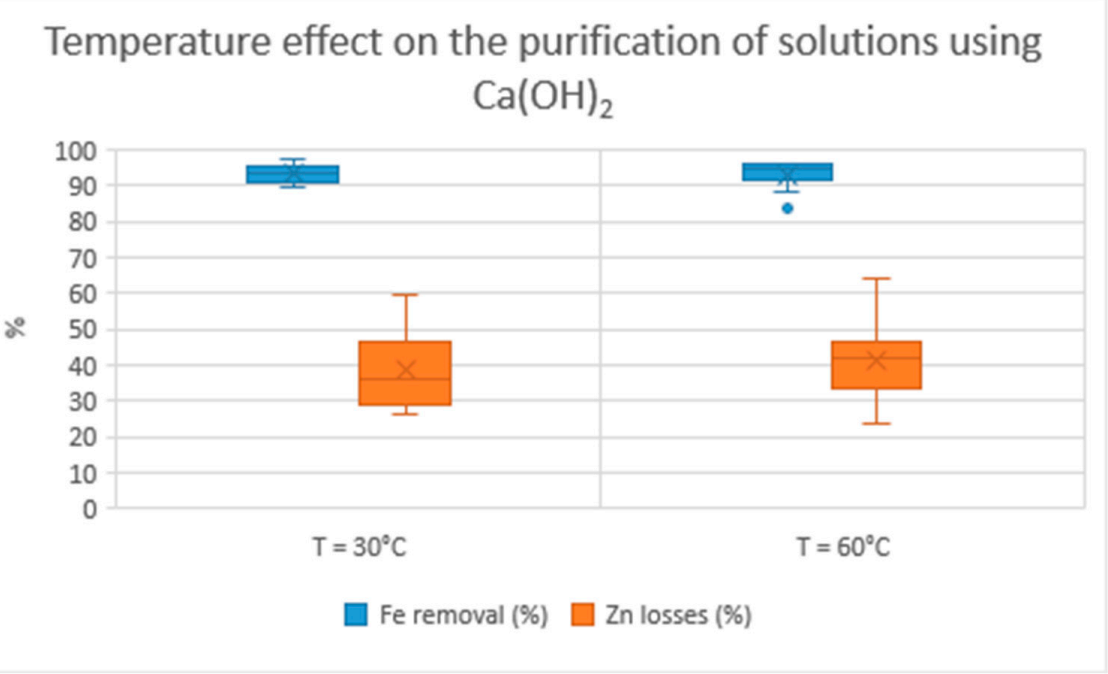

Figure 14. Temperature effect on the purification of solutions using $\mathrm{Ca}(\mathrm{OH})_{2}$.

The temperature has practically no influence on iron removal. In the case of zinc losses, a minimal impact on the averages is observed; nevertheless, there is a more excellent dispersion of the data. This is explained considering the effect of temperature-stirring, stirringtime, and temperature-stirring- $\mathrm{pH}$ interactions. The following treatment results should be noted: for a $\mathrm{pH}=4, \mathrm{~T}=60^{\circ} \mathrm{C}$, stirring speed $=300 \mathrm{rpm}$ and operating time $=10 \mathrm{~min}, 88.1 \%$ of iron removal and $23.7 \%$ of zinc losses is obtained. These results can be improved by a previous oxidation process and provide information for designing the purification process of industrial solutions.

Regarding the phase separation stage, slaked lime presented favorable conditions of homogeneity and quality of the filter cake. Experiments were conducted to determine the filtration speed in 1 pilot-scale batch operation. The estimated operating time was $27 \mathrm{~min}$ per batch.

Similarly, experimental treatments were developed based on a factorial design for $\mathrm{Na}_{2} \mathrm{CO}_{3}$. In this case, the levels of the experimentation were the following: $\mathrm{pH} 5,5.5$ and 6; temperature $30{ }^{\circ} \mathrm{C}$ and $50{ }^{\circ} \mathrm{C}$; stirring speed $300 \mathrm{rpm}$ and $400 \mathrm{rpm}$; time $10 \mathrm{~min}$ and $20 \mathrm{~min}$. The analysis of variance was performed with a significance level of 0.05 . No significant influencing factors were found for iron removal; however, the ranges in which the evaluated factors were manipulated ensure a high percentage of iron removal, which varies between $88 \%$ and $98 \%$. Zinc losses are significantly influenced by the reaction time $(\mathrm{F}=47.09, p$-value $=0.021)$ and the temperature-stirring $(\mathrm{F}=64.31, p$-value $=0.015)$, temperature-time $(\mathrm{F}=51.77, p$-value $=0.019)$ and stirring- $\mathrm{pH}(\mathrm{F}=35.18, p$-value $=0.028)$ interactions.

Figures 15 and 16 present box-and-whisker diagrams that show the effect of $\mathrm{pH}$ and temperature on iron removal and zinc losses using $\mathrm{Na}_{2} \mathrm{CO}_{3}$, based on the development of 24 experimental treatments.

The data presented in Figures 15 and 16 show the results of the analysis of variance. The $\mathrm{pH}$, with values between 5 and 6, does not influence the removal of iron and loss of zinc; it should be noted that the losses of $\mathrm{Zn}$ show more excellent dispersions, which is related to the effect of the temperature-stirring, temperature-time, and stirring-pH interactions. In the same way, the temperature does not significantly influence iron removal and Zn losses; however, the effect of the interactions is manifested in the dispersion of the percentage of $\mathrm{Zn}$ losses in the 2 temperature levels. The trend of the data indicates that it is possible to reduce the losses of $\mathrm{Zn}$ without affecting the removal of Fe. 


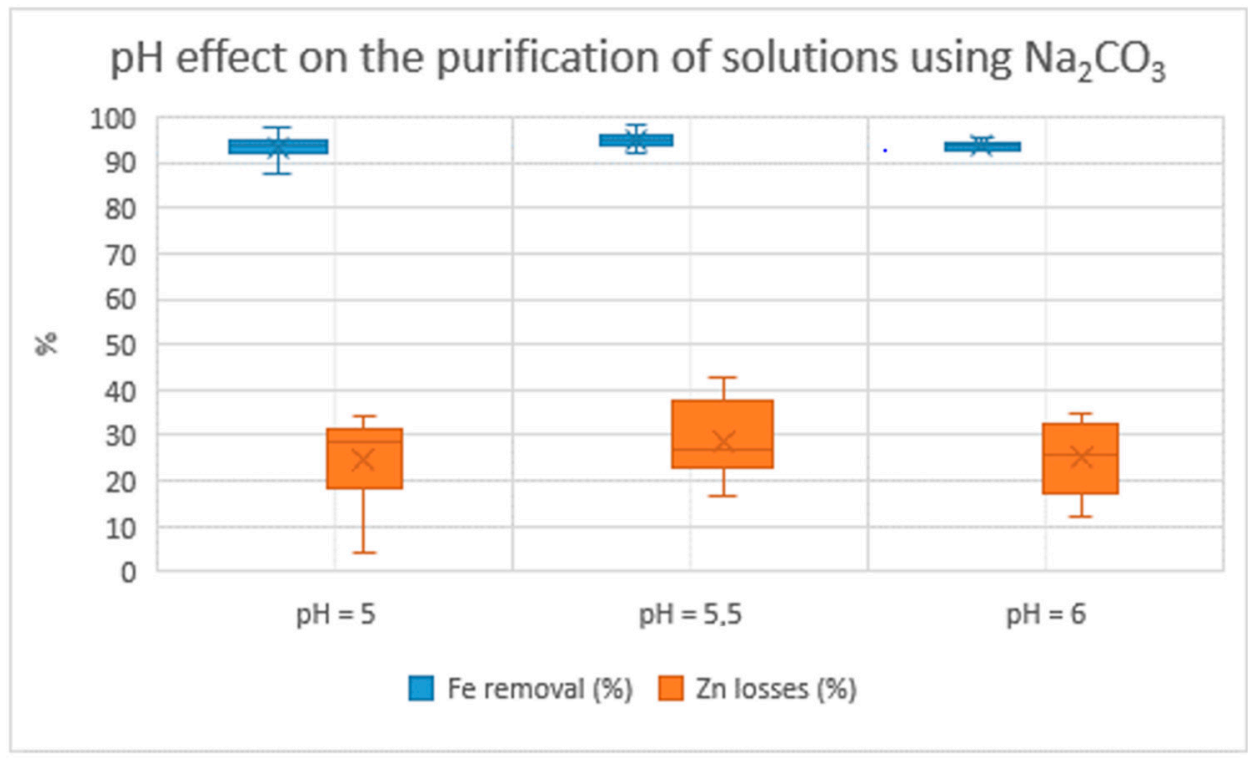

Figure 15. $\mathrm{pH}$ effect on the purification of solutions using $\mathrm{Na}_{2} \mathrm{CO}_{3}$.

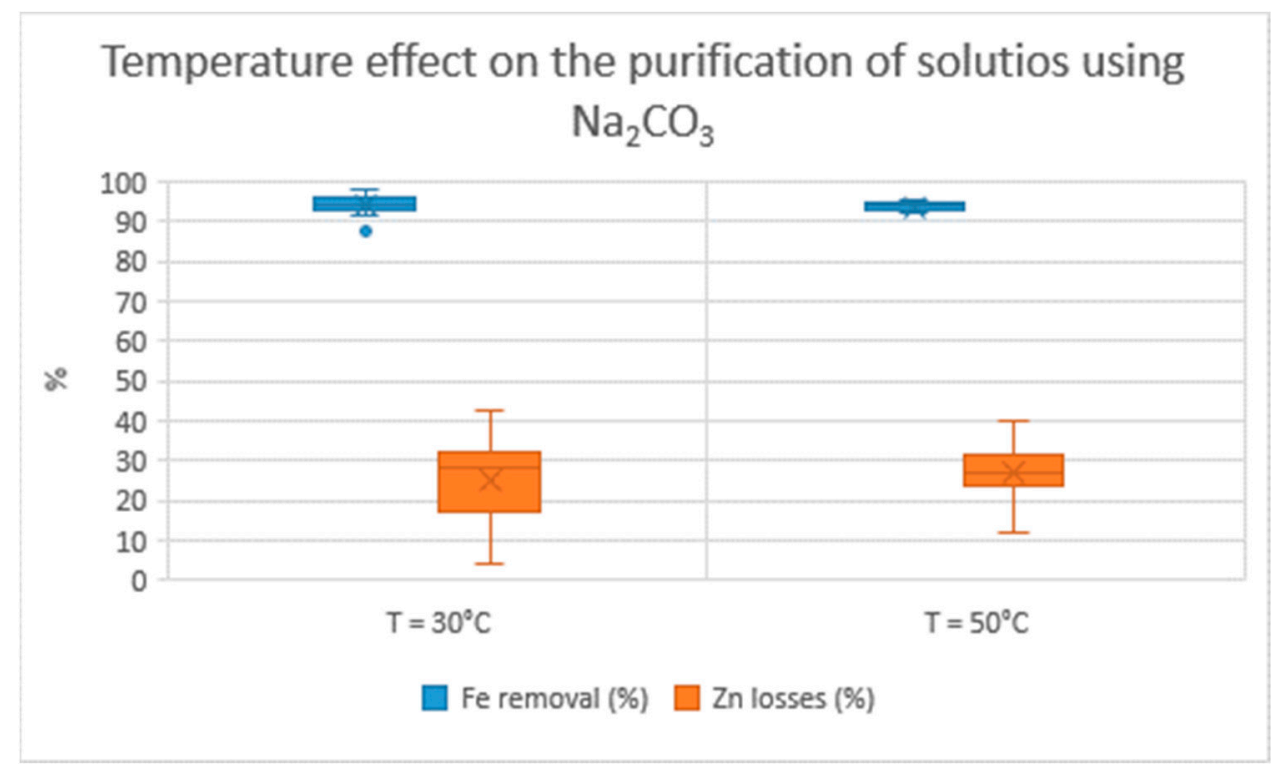

Figure 16. Temperature effect on the purification of solutions using $\mathrm{Na}_{2} \mathrm{CO}_{3}$.

As for the factors influencing the losses of $\mathrm{Zn}$, it can be indicated that a shorter reaction time increases the losses of $\mathrm{Zn}$. The treatment was carried out at $30{ }^{\circ} \mathrm{C}, 300 \mathrm{rpm}$, the reaction time of $20 \mathrm{~min}$ and $\mathrm{pH} 5$ stands out, obtaining 93.3\% removal of Fe and $4.4 \%$ losses of $\mathrm{Zn}$. The filtration rate determination was conducted on a laboratory scale for $\mathrm{Na}_{2} \mathrm{CO}_{3}$ pulps. With the results obtained, the filtration time of 1 pilot-scale batch operation was estimated, which turned out to be $15 \mathrm{~h}$ : evidencing the disadvantage of this reagent in terms of phase separation.

For $\mathrm{Na}_{2} \mathrm{CO}_{3}$, the transition from the colloidal zone to the non-colloidal area occurs at a high $\mathrm{pH}$, which establishes that the purification of solutions must be carried out in a $\mathrm{pH}$ range between 4.8 and 5, a range that makes it possible to maintain the losses of zinc under 20\%. The X-rays Diffraction Analysis (XRD) of solids evidenced the presence of a large proportion of amorphous solids, which must be controlled by reaction time. The difficulties in the separation of phases and the cost of the reagent make its application at an industrial level inadvisable. 


\subsection{Oxidation of Solutions and Determination of Operating Conditions}

Considering the results obtained in the 24 experimental treatments carried out for $\mathrm{Ca}(\mathrm{OH})_{2}$, to iron removal and zinc losses, and, taking into account the estimated phase separation time for 1 pilot-scale batch operation and the low cost of the reagent, an oxidation stage was incorporated before the solution purification process. According to what was indicated in the methodological aspects, $\mathrm{H}_{2} \mathrm{O}_{2}$ and $\mathrm{KMnO}_{4}$ were used, applying the reagents in the dosages indicated in said section. The oxidation reactions are presented in Equations (1) and (2).

For $\mathrm{Ca}(\mathrm{OH})_{2}$, the non-colloidal zone is identified from $\mathrm{pH}$ 3.9. According to the results of the experimental treatments, at $\mathrm{pH} 4$, iron removals greater than $90 \%$ can be achieved, depending on the operational conditions. Once the limit value of $\mathrm{pH}$ has been determined to ensure the removal of $\mathrm{Fe}$, the range of variation of the $\mathrm{pH}$ must be restricted to reduce the losses of $\mathrm{Zn}$. The technological challenge that guided the development of this work was to determine, for each reagent tested, the appropriate operating conditions to achieve iron removals greater than $90 \%$, keeping the $\mathrm{Zn}$ losses at values around $20 \%$. The $\mathrm{Zn}$ concentrate leaching solutions that were treated were characterized by high concentrations of Fe, between $5 \mathrm{~g} / \mathrm{L}$ and $23 \mathrm{~g} / \mathrm{L}$, with $\mathrm{Fe} / \mathrm{Zn}$ ratios between 0.1 and 0.5 , and the oxidation stage is incorporated to ensure a residual iron concentration of $50 \mathrm{ppm}$ [10].

In particular, the solution subjected to oxidation presented $40.3 \mathrm{~g} / \mathrm{L}$ of $\mathrm{Zn}$ and $12476 \mathrm{ppm}$ of Fe. Previously, it was subjected to the purification process without oxidation, achieving removal of $89 \% \mathrm{Fe}$ at $\mathrm{pH} 4.3,30.1 \%$ loss of $\mathrm{Zn}$ and a residual Fe concentration of $1372 \mathrm{ppm}\left(30^{\circ} \mathrm{C}, 300 \mathrm{rpm}\right.$, time $\left.10 \mathrm{~min}\right)$.

Figure 17 shows the effect of the oxidant on the residual iron concentration and Figure 18 shows the result of the oxidant on zinc losses. The $\mathrm{pH}$ ranged between 4.3 and 5.4; for potassium permanganate, the $\mathrm{pH}$ ranged between 4.1 and 5 .

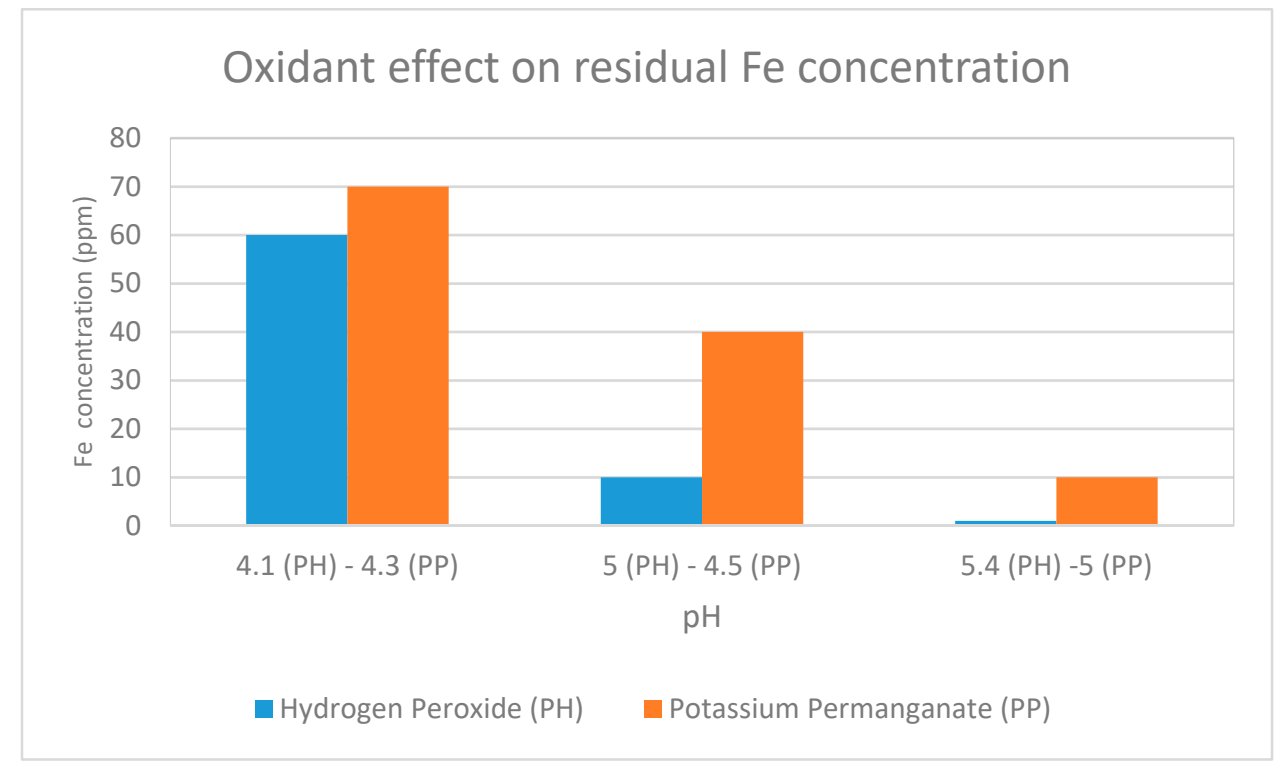

Figure 17. Oxidant effect on residual Fe concentration. 


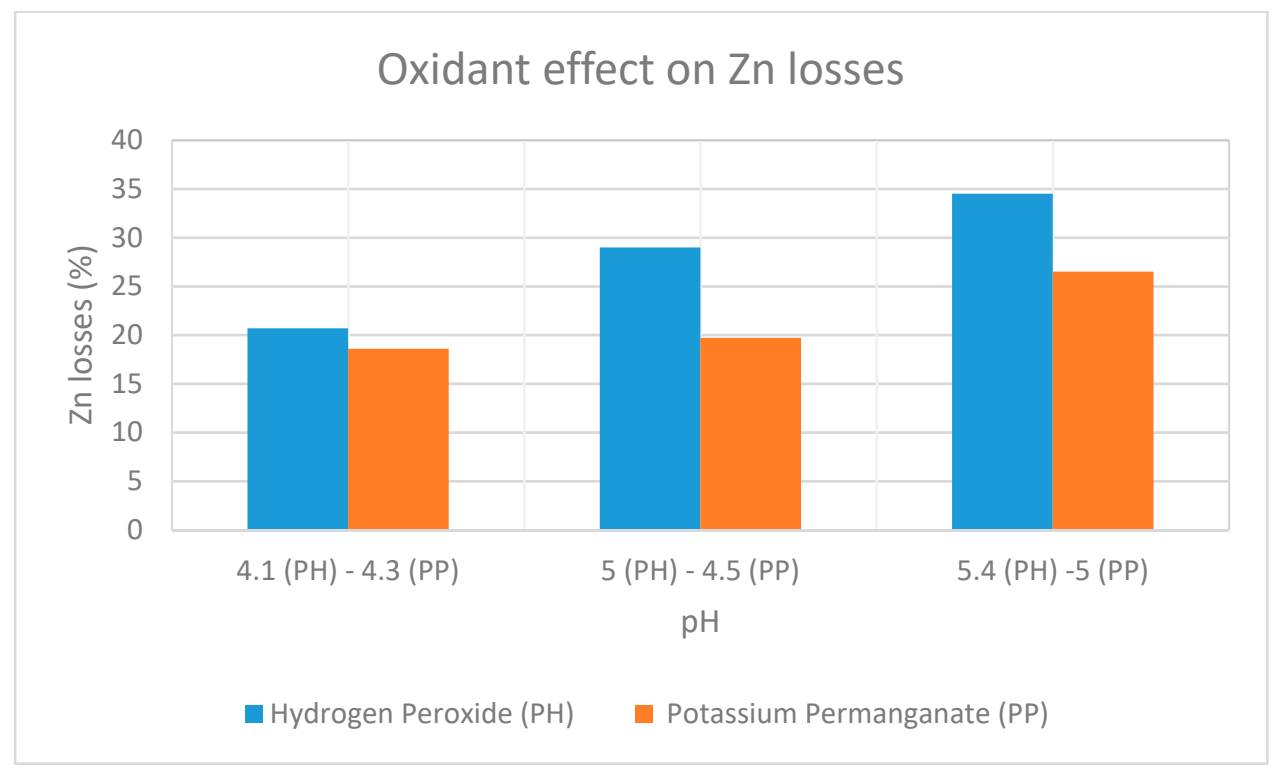

Figure 18. Oxidant effect on $\mathrm{Zn}$ losses.

Regarding iron removal, for hydrogen peroxide, a residual iron concentration in solution of $60 \mathrm{ppm}, 10 \mathrm{ppm}$ and $1 \mathrm{ppm}$ was achieved at $\mathrm{pH}$ 4.1, 5 and 5.4: accordingly. The zinc losses were $20.7 \%, 29 \%$ and $34.5 \%$, at $\mathrm{pH} 4.1,5$ and 5.4 ; respectively.

Using potassium permanganate, residual iron concentrations of $70 \mathrm{ppm}, 40 \mathrm{ppm}$ and $10 \mathrm{ppm}$ were achieved, at $\mathrm{pH} 4.3,4.5$ and 5: respectively. The $\mathrm{Zn}$ losses were $18.6 \%, 19.7 \%$ and $26.5 \%$ for the same $\mathrm{pH}$ values. The selected oxidant is potassium permanganate, considering that it achieves a residual concentration of Fe of $40 \mathrm{ppm}(99.7 \%$ removal $)$ and $\mathrm{Zn}$ losses of $19.7 \%$, at $\mathrm{pH} 4.5$ (ORP $800 \mathrm{mv}$ ). In addition, they are incorporating this oxidation stage, reducing the ratio (total $\mathrm{OH} / \mathrm{Fe}$ ) to $3.6,4.3$ and 4.5 at $\mathrm{pH} 4.3,4.5$ and 5 .

\section{Conclusions}

Of the six reagents used in the exploratory tests, the reagents $\mathrm{CaO}$ and sodium carbonate were the ones that provided the best zinc recovery and iron removal results. In the case of $\mathrm{CaO}$, iron removals of the order of $99.5 \%$ were recorded. In the case of sodium carbonate, zinc losses of the charge of $4.4 \%$ and iron removals of the order of $97.9 \%$ were obtained.

Although $\mathrm{CaO}$ was one of the reagents that yielded the best results in the exploratory tests, it presented operational difficulties in the filtration stage due to the high viscosity of the mixtures. Thus, it was decided to conduct tests with $\mathrm{Ca}(\mathrm{OH})_{2}$ (lime + water), obtaining zinc losses of $25 \%$ and iron removal of $95 \%$. Even though the performance indicators are lower than those obtained with $\mathrm{CaO}$; better results in the phase separation stage compensate for this. The experimental development on a laboratory scale concluded that the optimal ratio of water and lime is $2.5 \mathrm{~mL} / \mathrm{g}$ and its preparation is at room temperature due to the chemical characteristics of the lime used.

From the design of the pilot-scale phase separation equipment, it is concluded that the best reagent to use is slaked lime with an estimated operating time of $27 \mathrm{~min}$ per batch, which is contrasted with the estimated time for sodium carbonate of $15 \mathrm{~h}$.

To ensure a residual iron concentration in the filtered solutions at a level equal to or less than $50 \mathrm{ppm}$, an oxidation stage of the zinc sulfate solution obtained in the autoclave reactor was incorporated $\left(\mathrm{Fe}^{+2} / \mathrm{Fe}^{+3}\right.$ oxidation).

Using $\mathrm{KMnO}_{4}$, a solution is obtained under the parameters required for $\mathrm{EW}(\mathrm{Fe}<50 \mathrm{ppm})$. Of the reagents, slaked lime allows generating a zinc recovery of the order of $80 \%$ and an iron concentration below $50 \mathrm{ppm}$. The oxidation stage helps control the level of supersaturation, reducing zinc losses. 
It is recommended to use the slaked lime reagent due to its technical, economic, and operational feasibility. The operating parameters are $\mathrm{pH}=4.3$, water-lime ratio $=2.5 \mathrm{~mL} / \mathrm{g}$, and a previous oxidation stage with potassium permanganate at an ORP of $800 \mathrm{mv}$.

Author Contributions: Conceptualization, C.A.L., C.A.A., M.E.G., J.A.A. and G.E.F.; methodology, C.A.A. and G.E.F.; validation, M.E.G., J.A.A. and G.E.F.; formal analysis, C.A.L., M.E.G. and J.A.A.; investigation, C.A.L., C.A.A., M.E.G., J.A.A. and G.E.F.; data curation, J.A.A.; writing-original draft preparation, C.A.L. and M.E.G.; writing—review and editing, C.A.L. and M.E.G.; funding acquisition, C.A.L. and C.A.A. All authors have read and agreed to the published version of the manuscript.

Funding: This research was founded by INNOVA CORFO Project 15VEIID—45774 “Cátodos de Zinc ambientalmente amigables".

Data Availability Statement: All raw data remain the Universidad Católica del Norte property that allowed this study. The input data used to support the endings of this study could be available from the correspondent author's email with appropriate justification.

Acknowledgments: The authors wish to acknowledge the material support provided by Comercial Viacha and the financial support provided by Universidad Católica del Norte.

Conflicts of Interest: The authors declare no conflict of interest.

\section{References}

1. Sánchez, F.; Roa, C.; Garay, V.; Cantallopts, J. Exportación de Concentrados de Cobre: Caracterización De Condiciones Comerciales. Dirección de Estudios y Políticas Públicas; Gobierno de Chile: Santiago, Chile, 2021.

2. Fuentes, G.; Acuña, C.; Romo, S. Autoclave leaching zinc concentrate at bench scale. In Proceedings of the Conference of Metallurgists, Toronto, ON, Canada, 23-26 August 2015.

3. Boyanov, B.; Peltekov, A.; Petkova, V. Thermal behavior of zinc sulfide concentrates with different iron content at oxidative roasting. Thermochim. Acta 2014, 586, 9-16. [CrossRef]

4. Jarosz, P.; Kusiak, J.; Małecki, S.; Morkisz, P.; Oprocha, P.; Pietrucha, W.; Sztangret, L. An attempt at the optimization of the zinc production line. Arch. Civ. Mech. Eng. 2018, 18, 1116-1122. [CrossRef]

5. Bortot, F.E.; Balarini, J.C.; Rodrigues, E.M.; Santos, T.L.; Clark, A.E.; Martins, A.H.; Salum, A. Roasted zinc concentrate leaching Population balance modeling and validation. Hydrometallurgy 2018, 175, 208-217. [CrossRef]

6. Mureşan, L.; Maurin, G.; Oniciu, L.; Gaga, D. Influence of metallic impurities on zinc electrowinning from sulphate electrolyte. Hydrometallurgy 1996, 43, 345-354. [CrossRef]

7. Güler, E.; Seyrankaya, A. Precipitation of impurity ions from zinc leach solutions with high iron contents-A special emphasis on cobalt precipitation. Hydrometallurgy 2016, 164, 118-124. [CrossRef]

8. Nicol, M.; Akilan, C.; Tjandrawan, V.; Gonzalez, J.A. The effects of halides in the electrowinning of zinc. I. Oxidation of chloride on lead-silver anodes. Hydrometallurgy 2017, 173, 125-133. [CrossRef]

9. Liu, L.; Wang, M.; Wang, Z.; Zhang, Y. The influence of impurities on Gael electrowinning: Vanadium and iron. Hydrometallurgy 2014, 146, 76-81. [CrossRef]

10. Saba, A.; Elsherief, A. Continuous electrowinning of zinc. Hydrometallurgy 2000, 54, 91-106. [CrossRef]

11. Dutrizac, J.E.; Soriano, C. Behaviour of the rare earths during goethite $(\alpha-\mathrm{FeOOH})$ precipitation from sulphate-based solutions. Hydrometallurgy 2018, 176, 87-96. [CrossRef]

12. Masambi, S.; Dorfling, C.; Bradshaw, S. Comparing iron phosphate and hematite precipitation processes for iron removal from chloride leach solutions. Miner. Eng. 2016, 98, 14-21. [CrossRef]

13. Zhu, D.; Yang, C.; Pan, J.; Guo, Z.; Li, S. New pyrometallurgical route for separation and recovery of Fe, Zn, In, Ga and S from jarosite residues. J. Clean. Prod. 2018, 205, 781-788. [CrossRef]

14. Deng, Z.; Zhu, B.; Zeng, P.; Wei, C.; Li, X.; Li, C.; Fan, G. Behaviour and characterization of hematite process for iron removal in hydrometallurgical production. Can. Metall. Q. 2019, 58, 223-231. [CrossRef]

15. Ismael, M.R.C.; Carvalho, J.M.R. Iron recovery from sulphate leach liquors in zinc hydrometallurgy. Miner. Eng. 2003, 16, 31-39. [CrossRef]

16. Dutrizac, J.E.; Chen, T.T. Impurity incorporation in hematite precipitated from ferric sulphate solutions. World Metall. 2012, 65, 31-47.

17. Yan, S.; Qiu, Y. Preparation of electronic grade manganese sulfate from leaching solution of ferromanganese slag. Trans. Nonferrous Met. Soc. China 2014, 24, 3716-3721. [CrossRef]

18. Garside, J. Industrial crystallization from solution: State of the technique. Chem. Eng. Sci. 1985, 40, 3-26. [CrossRef]

19. Dirksen, J.A.; Ring, T.A. Fundamentals of crystallization: Kinetic effects on particle size distributions and morphology. Chem. Eng. Sci. 1991, 46, 2389-2427. [CrossRef]

20. Giulietti, M.; Seckler, M.; Derenzo, S.; Ré, M.; Cekinski, E. Industrial crystallization and precipitation from solutions: State of the technique. Braz. J. Chem. Eng. 2001, 18, 423-440. [CrossRef] 
21. Claassen, J.; Sandenbergh, R. Influence of temperature and $\mathrm{pH}$ on the quality of metastable iron phases produced in zinc-rich solutions. Hydrometallurgy 2007, 86, 178-190. [CrossRef]

22. Demopoulos, G.P. Aqueous precipitation and crystallization for the production of particulate solids with desired properties Hydrometallurgy 2009, 96, 199-214. [CrossRef]

23. Masindi, V.; Ndiritu, J.G.; Maree, J.P. Fractional and step-wise recovery of chemical species from acid mine drainage using cryptocrystalline magnesite nano-sheets: An experimental and geochemical modelling approach. J. Environ. Chem. Eng. 2018, 6, 1634-1650. [CrossRef]

24. Parkhurst, D.L.; Appelo, C.A.J. Description of Input and Examples for PHREEQC Version 3: A Computer Program for Speciation, Batch-Reaction, One-Dimensional Transport, and Inverse Geochemical Calculations (No. 6-A43); U.S. Geological Survey: Reston, VA, USA, 2013

25. Claassen, J.O.; Meyer, E.H.O.; Rennie, J.; Sandenbergh, R.F. Iron precipitation from zinc-rich solutions: Defining the Zincor Process. Hydrometallurgy 2002, 67, 87-108. [CrossRef]

26. Benjamin, M.M.; Leckie, J.O. Multiple-site adsorption of $\mathrm{Cd}, \mathrm{Cu}, \mathrm{Zn}$, and $\mathrm{Pb}$ on amorphous iron oxyhydroxide. J. Colloid Interface Sci. 1981, 79, 209-221. [CrossRef]

27. Stumm, W.; Morgan, J.J. Aquatic Chemistry: Chemical Equilibria and Rates in Natural Waters, 3rd ed.; Wiley Interscience: Hoboken, NJ, USA, 1996; 1040p.

28. Jambor, J.L. The Relationship of mineralogy to acid-and neutralization-potential values in ARD. In Environmental Mineralogy, Microbial Interactions, Anthropogenic Influences, Contaminated Land and Waste Management: The Mineralogical Society Series; Mineralogical Society: London, UK, 2000; pp. 19-58. [CrossRef]

29. Dold, B. Mineralogical and Geochemical Changes of Cooper Flotation Tailings in Relation to Their Original Composition and Climatic Setting: Implications for Acid Mine Drainage and Element Mobility. Ph.D. Thesis, Université de Genéve, Geneva, Switzerland, 1999. [CrossRef]

30. Li, B.; Wei, Y.; Wang, H.; Yang, Y.; Yin, Y. Preparation of $\mathrm{ZnSO}_{4} \cdot 7 \mathrm{H}_{2} \mathrm{O}$ and Separation of Zinc from Blast Furnace Sludge by Leaching-Purification-Crystallization Method. ISIJ Int. 2019, 59, 201-207. [CrossRef]

31. Monhemius, A.J. THE IRON ELEPHANT: A Brief History of Hydrometallurgists' Struggles with Element No. 26. In Proceedings of the XXVIII International Mineral Processing Congress, Quebec City, PQ, Canada, 11-15 September 2016.

32. Shinoda, M.; Yamaguchi, T.; Murai, R.; Sumi, I. Development of Zinc-separating Process of Blast Furnace Dust using Hydrometallurgical System. Tetsu Hagane 2019, 105, 847-853. [CrossRef]

33. Mukongo, T.; Maweja, K.; Ngalu, B.; Mutombo, I.; Tshilombo, K. Zinc recovery from the water-jacket furnace flue dusts by leaching and electrowinning in a SEC-CCS cell. Hydrometallurgy 2009, 97, 53-60. [CrossRef]

34. Mangunda, C.T.; Petersen, J.; Lewis, A.E. Modifying the dewatering behaviour of iron solids from ferric sulphate solutions during lime treatment. Hydrometallurgy 2020, 191, 105238. [CrossRef]

35. Rudnik, E. Investigation of industrial waste materials for hydrometallurgical recovery of zinc. Miner. Eng. 2019, $139,105871$. [CrossRef]

36. Langová, Š.; Riplová, J.; Vallová, S. Atmospheric leaching of steel-making wastes and the recipitation of goethite from the ferric sulphate solution. Hydrometallurgy 2007, 87, 157-162. [CrossRef]

37. Langová, S.; Matýsek, D. Zinc recovery from steel-making wastes by acid pressure leaching and hematite precipitation. Hydrometallurgy 2010, 101, 171-173. [CrossRef]

38. Birchal, V.S.; Rocha, S.D.F.; Mansur, M.B.; Ciminelli, V.S.T. A simplified mechanistic analysis of the hydration of magnesia. Can. J. Chem. Eng. 2001, 79, 507-511. [CrossRef]

39. Wang, K.; Zhang, Q.; Hu, H.; Liu, Y. Efficient removal of iron (II) from manganese sulfate solution by using mechanically activated $\mathrm{CaCO}_{3}$. Hydrometallurgy 2019, 188, 169-173. [CrossRef] 